\title{
RMetS
}

\section{A 'hurricane-like' polar low fuelled by sensible heat flux: high-resolution numerical simulations}

\author{
Ivan Føre, ${ }^{\text {a*}}$ Jón Egill Kristjánsson, ${ }^{\text {a Erik W. Kolstad, },{ }^{b, c} \text { Thomas J. Bracegirdle, }}{ }^{\mathrm{d}}$ \\ Øyvind Saetra ${ }^{\mathrm{e}}$ and Bjørn Røsting ${ }^{\mathrm{e}}$ \\ ${ }^{a}$ Department of Geosciences, University of Oslo, Blindern, Oslo, Norway \\ ${ }^{\mathrm{b}}$ Uni Research ASBergen, Norway \\ ${ }^{\mathrm{B}}$ Bjerknes Centre for Climate Research, Bergen, Norway \\ ${ }^{\mathrm{d}}$ British Antarctic Survey, Cambridge, UK \\ ${ }^{\mathrm{e}}$ The Norwegian Meteorological Institute, Blindern, Oslo, Norway \\ ${ }^{\star}$ Correspondence to: I. Føre, University of Oslo, Department of Geosciences, P.O. Box 1047 Blindern, Oslo, 0316, \\ Norway. E-mail: ifore@geo.uio.no
}

An unusually deep $(961 \mathrm{hPa})$ hurricane-like polar low over the Barents Sea during 18-21 December 2002 is studied by a series of fine-mesh $(3 \mathrm{~km})$ experiments using the Weather Research and Forecasting (WRF) model. The simulated polar low was similar to hurricanes and similar previous case-studies in that it had a clear, calm and warm eye structure surrounded by moist convection organized in spiral cloud bands, and the highest surface wind speeds were found in the eye wall. The proximity to the sea ice and the high surface wind speeds (about $25 \mathrm{~m} \mathrm{~s}^{-1}$ ) during the deepening stage triggered extremely high surface sensible and latent heat fluxes at the eye wall of about 1200 and $400 \mathrm{~W} \mathrm{~m}^{-2}$, respectively. As the polar low moved eastward and weakened, maximum surface sensible and latent heat fluxes dropped to about 600 and $300 \mathrm{~W} \mathrm{~m}^{-2}$, respectively. Two types of sensitivity experiments were designed to analyse the physical properties of the polar low. Firstly, physical processes such as condensational heating and sensible and/or latent heat fluxes were switched off-on throughout the simulation. In the second type, these processes were turned off-on after the polar low had reached its peak intensity, which minimized the deformation of the polar-low environment, making it suitable to study the direct effect of physical processes on the mature vortex. The experiments suggest that the deepening stage of the polar low was dominated by baroclinic growth and that upper-level potential vorticity forcing contributed throughout its life cycle. After the deepening stage, the baroclinicity vanished and the polar low was fuelled by surface sensible heat fluxes while latent heat fluxes played a minor role. Condensational heating was not essential for the energetics of the polar low. Surprisingly, in experiments where condensational heating was turned off throughout the simulation, the polar low intensified. Copyright (c) 2012 Royal Meteorological Society

Key Words: polar lows; numerical experiments; air-sea interactions; upper-level forcing

Received 1 October 2010; Revised 19 September 2011; Accepted 12 December 2011; Published online in Wiley Online Library 6 February 2012

Citation: Føre I, Kristjánsson JE, Kolstad EW, Bracegirdle TJ, Saetra Ø, Røsting B. 2012. A 'hurricane-like’ polar low fuelled by sensible heat flux: high-resolution numerical simulations. Q. J. R. Meteorol. Soc. 138: 1308-1324. DOI:10.1002/qj.1876 


\section{Introduction}

The Nordic Seas (i.e. the Greenland, Norwegian and Barents Seas) experience severe maritime weather during winter, especially in the form of polar lows that often develop during northerly marine cold air outbreaks (MCAO) (Kolstad, 2006; Bracegirdle and Gray, 2008; Kolstad and Bracegirdle, 2008). Their appearances and generation mechanisms vary (e.g. Wilhelmsen, 1985; Businger and Reed, 1988; Bracegirdle and Gray, 2008), but a common feature of most types of polar low is that they are short-lived ( $<24$ hours), mesoscale $(200-1000 \mathrm{~km})$ cyclones with surface wind speeds above gale force (Rasmussen and Turner, 2003).

Because some polar lows are similar to tropical hurricanes in appearance and structure, polar lows have been referred to as 'extra-tropical hurricanes' (Rasmussen, 1979), 'Arctic hurricanes' (Emanuel and Rotunno, 1989; Businger and Baik, 1991), and 'hurricane-like polar lows' (Nordeng and Rasmussen, 1992). A common feature for polar lows and hurricanes is a typically clear and calm warm eye with large gradients of wind speed and temperature at the eye wall and spiral-like convective cloud bands ending at the edge of the warm core. For simplicity's sake, we refer to polar lows that resemble hurricanes as 'hurricane-like' polar lows despite the fact that their forcing mechanisms are not identical.

Unlike tropical hurricanes, most polar lows (Businger and Baik, 1991; Nordeng and Rasmussen, 1992; Grønås and Kvamstø, 1995) initially form in shallow baroclinic environments. According to Montgomery and Farrell (1992), upper-level lows or troughs (i.e. upper-level potential vorticity (PV) anomalies) are needed in order to initiate the surface developments. This requirement was demonstrated by Grønås and Kvamstø (1995) in a numerical study of four different MCAOs over the Norwegian Sea where upper-level PV anomalies interacting with low-level atmospheric instability were found to be essential for the development of polar lows. A PV inversion carried out by Føre et al. (2011) supported by dropsonde observations suggested that strong upper-level PV forcing was essential during the life cycle of a polar-low development over the Norwegian Sea during 3-4 March 2008. Bracegirdle and Gray (2009) used a PV inversion method to analyse the role of upper-level PV forcing on a polar low over the Norwegian Sea during 13-14 October 1993. They suggested that upper-level PV forcing initiated the polar low, but as the polar low matured, surface energy fluxes (e.g. Craig and Gray, 1996) became the main energy source. However, using the MM5 model, Martin and Moore (2006) demonstrated that surface energy fluxes were irrelevant for the intensity of a polar low over the Labrador Sea. Based on numerical experiments with the same model, Bresch et al. (1997) suggested that upper-level PV forcing interacting with lowlevel baroclinicity initiated a polar low over the Bering Sea during 7 March 1997, but that surface energy fluxes were also important for the initiation and energetics of polar-low development. Thus, it is commonly understood that upperlevel PV forcing interacting with low-level baroclinicity initiates most polar-low developments. However, at later stages a complex interplay between upper-level PV forcing, baroclinic instability, condensational heating, and surface energy fluxes may vary from case to case.

In order to improve our knowledge about hurricanelike polar lows, we here investigate an unusually intense hurricane-like polar-low development that took place during 18-21 December 2002 over the Barents Sea. Due to the scarcity of observational data for the area over the Barents Sea, numerical sensitivity experiments are a useful tool to investigate the underlying physics of the polar low. Running such experiments with global models is costly. Therefore, in the present study we rely on high-resolution numerical experiments with the full-physics version of the state-of-the-art Weather Research and Forecasting (WRF) model (see section 2). The regional WRF model is a costeffective model suitable for such research purposes with its built-in functions for turning off physical processes such as condensational heating and/or surface energy fluxes.

A drawback of most previous case-studies of hurricanelike polar lows is that the role of surface energy fluxes and condensational heating has been analysed using regional models with coarser horizontal and vertical resolution than in today's models (e.g. Rasmussen, 1979; Emanuel and Rotunno, 1989). Running the UK Met Office unified model (UM) for a polar low that took place during 3-4 March 2008 over the Norwegian Sea, McInnes et al. (2011) demonstrated that the decrease of the horizontal grid spacing from 12 to $4 \mathrm{~km}$ and then to $1 \mathrm{~km}$ significantly improved the simulation of the polar-low development. Indications of the improved model performance at higher resolution were found to be connected to the model's handling of convection. The use of the WRF model with a high number of vertical levels (51) as well as a high horizontal resolution (3 km mesh) is believed to improve the simulation of physical processes important for the polar-low development. In addition, the role of surface energy fluxes or condensational heating in hurricane-like polar lows has been discussed without rigorous numerical backing (e.g. Businger and Baik, 1991; Nordeng and Rasmussen, 1992). In other polar-low casestudies (e.g. Bresch et al., 1997), both latent heat and sensible heat fluxes were turned off at the same time throughout the whole integration time in sensitivity experiments, precluding an analysis of the role of each individual type of surface energy flux and condensational heating. Thus, in this study, we use high horizontal resolution WRF sensitivity experiments to investigate the role of both types of surface energy flux separately and of their combined effect and that of condensational heating, in order to analyse the physical properties of the polar low (see section 5).

A disadvantage of many sensitivity studies, such as the experiments discussed above, is that various physical properties such as condensational heating and/or surface energy fluxes are turned off throughout the whole integration time (Craig and Gray, 1996; Bresch et al., 1997; McInnes et al., 2011). An absence of a certain physical process for a long time (more than a day) affects not only the vortex itself but also the environment in which the vortex develops. In such experiments, with increasing integration time, it is difficult to judge whether the removal of a certain physical process affects the polarlow intensity directly or indirectly through modification of the environment that the polar low develops within (e.g. Yanase et al., 2004). Therefore, in addition to the more commonly used sensitivity experiments described above, we also apply the new type of sensitivity experiment introduced by Yanase et al. (2004). In our study, the physical processes are turned off (see section 2) after the polar low has reached peak intensity. If a physical process has a direct effect on the polar low itself, we should observe differences in polar-low intensity after 1-3 hours of integration (Yanase et al., 2004). 
Based on these new types of sensitivity experiments, we will discuss which physical process are directly important for the mature polar-low intensity and how they affect the polar-low intensity after the environment conditions have been set up (section 5).

\section{Model description and experiment design}

\subsection{The numerical model}

The WRF model is a mesoscale numerical weatherprediction system used worldwide in operational forecasting and atmospheric research. It integrates non-hydrostatic, compressible dynamical equations with an Arakawa Cgrid using a terrain-following vertical coordinate with two-way nesting. In this study, version 2.2.1 of the WRF (Skamarock et al., 2007) was used. The following physical parametrizations were used for the full-physics experiments: the Thompson bulk microphysics scheme (Thompson et al., 2004, 2006); the Betts-Miller-Janjić moist convection scheme (Janjić, 1994, 1996); the Yonsei University planetary boundary layer (PBL) scheme (Hong et al., 2006); the Noah Land Surface model (Chen and Dudhia, 2001); the MM5 similarity surface scheme; the rapid radiative transfer model look-up table (Mlawer et al., 1997); and the Dudhia longwave and short-wave radiation schemes (Dudhia, 1989). According to Claud et al. (2004), the simulated polar-low track can be sensitive to the number of vertical levels in the PBL. For this reason, and to increase the resolution of physical processes in the PBL crucial for polar-low developments, 18 of the 51 vertical levels used in this study were set below $850 \mathrm{hPa}$. All simulations were carried out with positive-definite advection of scalars, moisture, and turbulent kinetic energy.

A later version of the WRF model (version 3) was recently applied in a polar-low study by $\mathrm{Wu}$ et al. (2011) in which National Centers for Environmental Prediction (NCEP) analyses $\left(1^{\circ} \times 1^{\circ}\right.$ latitude-longitude grid) were used as initial and lateral boundary conditions. According to Renfrew et al. (2002), NCEP analyses overestimate both wind speed and surface fluxes over sea, while European Centre for Medium-range Weather Forecasts (ECMWF) analyses are within the bounds of observational uncertainties. Furthermore, in NCEP analyses, the polar low studied here makes landfall too early (not shown) according to satellite observations (see section 3) and is therefore not suitable for this case-study. Thus, we use ECMWF T511 data with $0.5^{\circ} \times 0.5^{\circ}$ latitude-longitude horizontal grid resolution as the initial and lateral boundary conditions. As will be shown, the ECMWF analyses positioned the polar low quite accurately (see section 3 ). In Figure 1, the black square shows the $9 \mathrm{~km}$ parent domain and the red square shows the $3 \mathrm{~km}$ nested domain. The location of the ice edge was held constant throughout the simulations (blue line, Figure 1).

\subsection{Experiment design}

A series of sensitivity experiments were carried out in order to reveal the underlying physics of the polar low. The experiments are listed in Table 1, and we describe here their main features.

Initially, sensitivity experiments in which a physical process was turned off throughout the whole simulation were

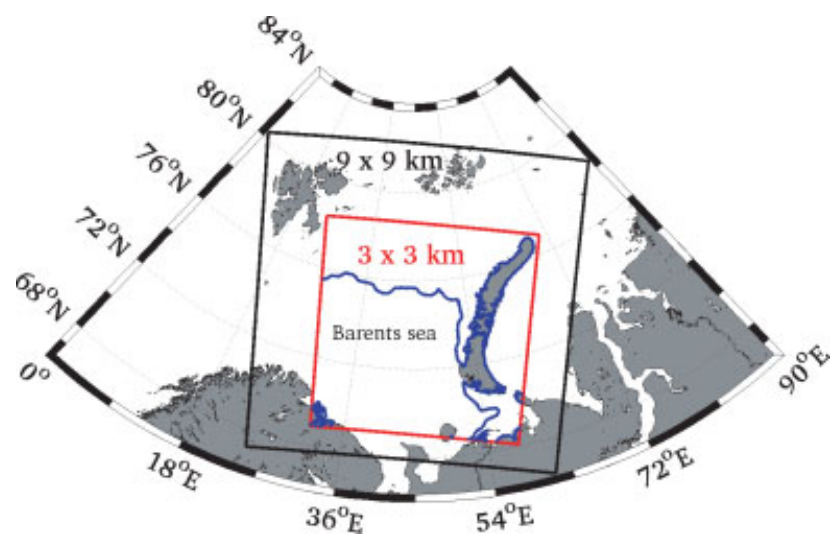

Figure 1. The computational domains. The black square indicates the parent domain $(9 \times 9 \mathrm{~km})$ and the red square indicates the nested domain $(3 \times 3 \mathrm{~km}$ grid spacing). The sea ice edge in the nested domain is shown as a blue line.

Table 1. A summary of the characteristics of each model experiment. The description of each experiment describes the differences to the CTL experiment.

\begin{tabular}{ll}
\hline Abbreviation & Description \\
\hline CTL & The default control model experiment. \\
CTL+NoCH & Condensational heating was turned off. \\
CTL+NoCH-D & Condensational heating was turned off at \\
& 1200 UTC 19 December and thereafter. \\
CTL + NoCv & The convection scheme was turned off. \\
CTL + NoCv + NoCH & The convection scheme and condensational \\
& heating were turned off.
\end{tabular}

WSM6

The WRF single-moment 6-class microphysics scheme was used.

WSM6+NoCH

The WRF single-moment 6-class microphysics scheme was used and condensational heating was turned off.

WSM6+NoCH-D

The WRF single-moment 6-class microphysics scheme was used and condensational heating was turned off at 1200 UTC 19 December and thereafter.

WSM6+NoCv

The WRF single-moment 6-class microphysics scheme was used and the convection scheme was turned off.

WSM6+NoCv+NoCH The WRF single-moment 6-class microphysics scheme was used, and the convection scheme and condensational heating were turned off.

NoF Surface energy fluxes of sensible heat and latent heat were turned off over the sea. Surface energy fluxes of sensible heat and latent heat were turned off over the sea at 1200 UTC 19 December and thereafter.

NoSHF

The sensible heat flux was turned off over the sea.

NoSHF-D The sensible heat flux was turned off over the sea at 1200 UTC 19 December and thereafter. The latent heat flux was turned off over the sea.

NoLHF-D

The latent heat flux was turned off over the sea at 1200 UTC 19 December and thereafter. $\mathrm{NoF}+\mathrm{NoCH}$ Condensational heating as well as sensible and latent heat fluxes over the sea were turned off.

designed. First, the full-physics control (CTL) experiment as described above was carried out. To test the sensitivity to the treatment of cloud microphysics, the WRF Single-Moment 6-class (Hong and Lim, 2006) scheme was used (WSM6). 
This scheme reproduced the cloud and precipitation processes more realistically than the Thompson scheme during WRF simulations of two polar-low cases over the Sea of Japan (Wu and Petty, 2010). The most important differences between the schemes is that in the Thompson scheme, the assumed snow size distribution depends on both ice water content and temperature, and all species assume a generalized gamma distribution instead of a purely exponential distribution.

To test the polar-low sensitivity to the treatment of convective processes in the model, two simulations identical to the CTL and the WSM6 experiments were designed with the convection scheme $(\mathrm{Cv})$ turned off $(\mathrm{CTL}+\mathrm{NoCv}$ and WSM6+NoCv). By turning off condensational heating $(\mathrm{NoCH})$ in the above experiments, the role of atmospheric latent heat release for the polar-low development was investigated $(\mathrm{CTL}+\mathrm{NoCH}, \mathrm{CTL}+\mathrm{NoCv}+\mathrm{NoCH}$ and $\mathrm{WSM} 6+\mathrm{NoCH}, \mathrm{WSM} 6+\mathrm{NoCv}+\mathrm{NoCH})$. This was done by turning off the heat contribution to the atmospheric temperature profile given by the microphysics schemes after each integration time step. All other processes in the cloud microphysics schemes were carried out normally.

A second group of four experiments was performed to test the sensitivity to surface energy fluxes. First, an experiment with no surface energy fluxes (NoF) was carried out. Two similar experiments were then conducted to test the sensitivity to removal of only sensible heat fluxes (NoSHF) or only latent heat fluxes (NoLHF) over the sea. To isolate the role of baroclinicity, an experiment with no surface energy fluxes and no condensational heating was performed $(\mathrm{NoF}+\mathrm{NoCH})$.

Following the new type of sensitivity experiment discussed in the introduction, a third group of experiments was designed in which various physical processes (condensational heating and sensible and/or latent heat fluxes) were artificially shut off at later times. This was done by restarting the WRF model about 3 hours after the polar low had reached peak intensity using the CTL run as initial conditions. The abbrevations for these experiments end with a capital D (delayed). In these delayed (CTL+NoCH-D, WSM6+NoCH-D, NoF-D, NoSHF-D, NoLHF-D) experiments the influence of the physical processes on the mature polar-low intensity is more clearly revealed.

Sensitivity experiments (not shown) revealed that the WRF model performance was optimal when the simulations were initiated about 36 hours prior to the first signatures of the polar low, which is in agreement with the result of the UM model simulations of a polar low over the Norwegian Sea during 3-4 March 2008 presented in McInnes et al. (2011). For this reason, all simulations of the polar low, except for the delayed (D) experiments described below, were initialized at 0000 UTC on 17 December and ended at 1200 UTC on 21 December. Allowing for spin-up time, only data from 0000 UTC on 18 December and onwards from the $3 \mathrm{~km}$ mesh are presented.

\section{Synoptic overview}

This section describes the synoptic-scale and mesoscale evolution during the period from 1200 UTC on 17 December 2002 to 1200 UTC on 21 December 2002, spanning the pre-development stage and the full life cycle of the polar low. The synoptic overview is based on infrared images from the Advanced Very High Resolution Radiometer (AVHRR) instrument on board the National Oceanic and Atmospheric Administration (NOAA) polar-orbiting satellites, as well as ECMWF analyses.

Satellite images and mean-sea-level pressure (MSLP) in the ECMWF analyses show that the precursor of the polarlow development was a synoptic-scale low $(980 \mathrm{hPa})$ situated off the coast of northern Norway at about 1200 UTC on 17 December $\left(72^{\circ} \mathrm{N}, 12^{\circ} \mathrm{E}\right.$, Figure $\left.2(\mathrm{a})\right)$.

During the next 24 hours, this low moved northeast as it weakened. A satellite image valid at 1441 UTC on 18 December shows that the remnant of the synoptic-scale low is located west of Novaya Zemlya at about $73^{\circ} \mathrm{N}, 45^{\circ} \mathrm{E}$ over the Barents Sea (Figure 2(b)). Closer inspection of the satellite image (Figure 2(b)) shows lines of clouds (i.e. cloud streets) downstream of the sea ice edge, which is evidence of MCAO. The cyclonic cloud features seen at $73^{\circ} \mathrm{N}, 45^{\circ} \mathrm{E}$ suggest that an eye-like structure is under formation. This is believed to be the first signature of polar development, indicating that the polar low flares up within the inner core of an occluded synoptic-scale low, which is not common for polar lows. However, previous studies of hurricane-like polar lows suggest that some of them originate within old synoptic occlusions (Rasmussen and Turner, 2003). The differences in position between the developing eye and the closed isobars $(969 \mathrm{hPa})$ seen in the ECMWF analysis suggest that the polar low is placed somewhat too far north in the analysis (Figure 2(b)).

Based on the large gradients of $1000-500 \mathrm{hPa}$ thickness and the $500 \mathrm{hPa}$ height, we suggest that as the synopticscale low enters the Barents Sea, it sets up a deep baroclinic zone, separating relatively warmer sub-polar air south in the Barents Sea from Arctic air masses further north (Figure 3(a) and (b)). The $500 \mathrm{hPa}$ height shows that during the same time period, the upper-level low $(4750 \mathrm{~m})$ seen north of Novaya Zemlya centred at about $80^{\circ} \mathrm{N}, 60^{\circ} \mathrm{E}$ (Figure $3(\mathrm{a})$ ) prior to the polar-low development moved to the southwest and was positioned east of Svalbard at 1200 UTC on 18 December $\left(77^{\circ} \mathrm{N}, 30^{\circ} \mathrm{E}\right.$, Figure $\left.3(\mathrm{~b})\right)$.

At 0213 UTC on 19 December, the satellite image shows an intense hurricane-like polar low with a well-defined cloud-free eye at about $74^{\circ} \mathrm{N}, 47^{\circ} \mathrm{E}$ (Figure 2(c)), with cyclonical cloud bands wrapped around the eye. Based on the closed isobars, the ECMWF model still places the polar low too far north, but confirms its deepening (963 hPa). The 1000-500 hPa thickness suggests that the polar low is located on the warm side of the north-south oriented baroclinic zone (Figure 3(c)). Both 1000-500 hPa thickness and $500 \mathrm{hPa}$ height suggest that cold air advection takes place to the rear of the developing polar low (Figure 3(b) and (c)), which probably explains why the upper-level low has moved southeast and its centre is now found southwest of the polar low at about $73^{\circ} \mathrm{N}, 40^{\circ} \mathrm{E}$ (Figure $3(\mathrm{c})$ ). The tilt between the upper-level low (500 hPa height) and the polar low (MSLP) clearly demonstrates the baroclinic nature of the evolution.

Twenty-four hours later, satellite images reveal that the polar low bears a striking resemblance to a tropical hurricane, with spiral cloud bands surrounding a cloud-free eye at about $73^{\circ} \mathrm{N}, 49^{\circ} \mathrm{E}$ (Figure $2(\mathrm{~d})$ ). The brightness of the spiral cloud bands suggests that deep moist convection was taking place, thus condensational heating may be an important forcing mechanism for the polar low (see section 5). However, at this time, the analysed MSLP suggests that the polar low has weakened $(966 \mathrm{hPa})$, but according 

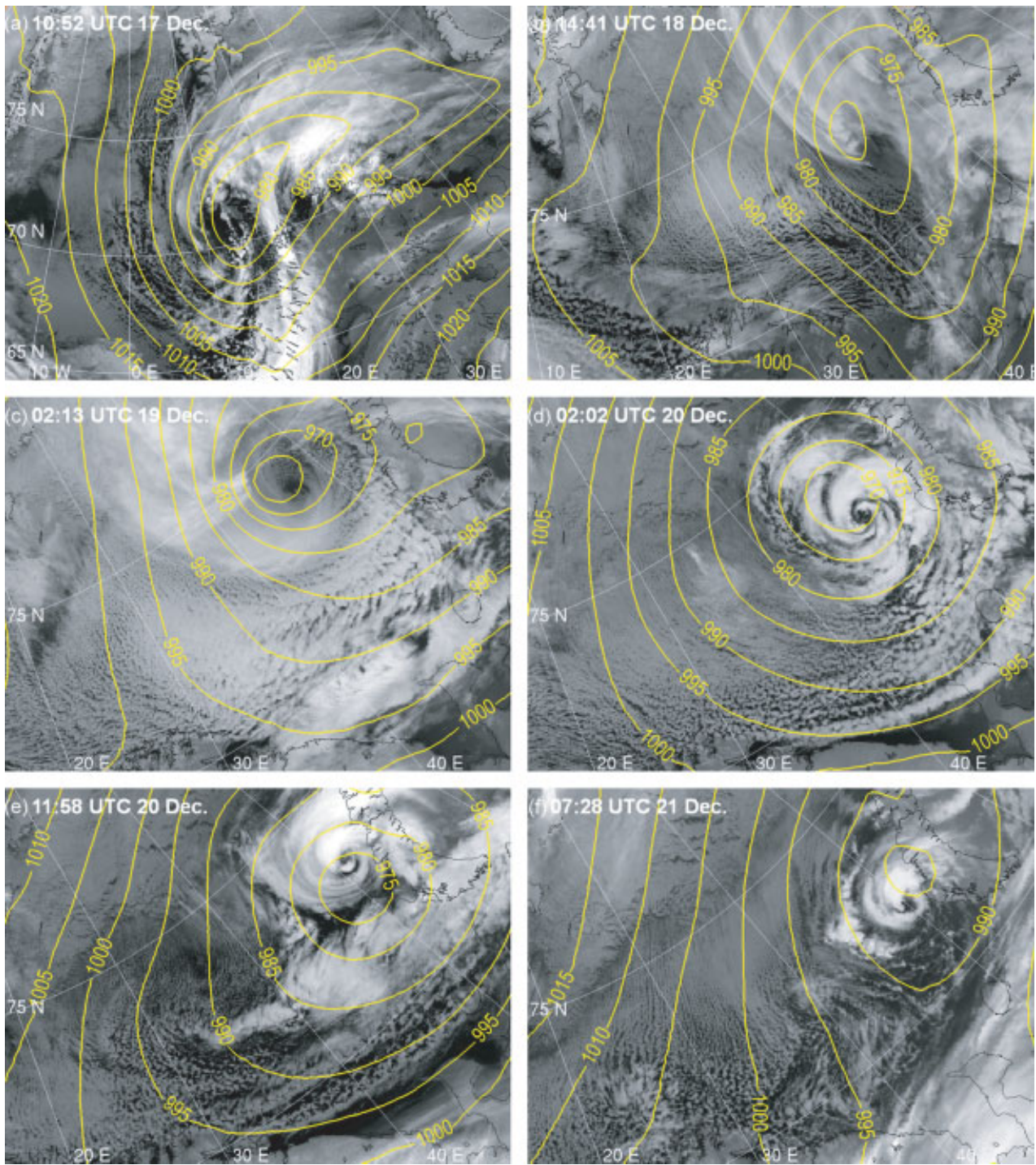

Figure 2. NOAA satellite images (infrared channel 4) showing the temporal development of the polar low. Superimposed on the satellite images is the ECMWF mean-sea-level pressure (MSLP, yellow lines, hPa) at roughly the same times. Satellite images are shown for (a) 1052 UTC 17 December 2002 along with MSLP from the 1200 UTC analysis; (b) 1441 UTC 18 December with MSLP from the 1200 UTC analysis; (c) 0213 UTC 19 December with MSLP from the 0000 UTC analysis; (d) 0202 UTC 20 December with MSLP from the 0000 UTC analysis; (e) 1158 UTC 20 December with MSLP from the 1200 UTC analysis, and (f) 0728 UTC 21 December with MSLP from the 0600 UTC analysis. Time for each satellite image is seen in the upper left corner. Coastlines are shown in black.

to the cloud-free eye seen in the satellite images and the closed isobars, it is located too far north in the ECMWF analysis. Based on the small size of the observed eye in the satellite images, tighter pressure (MSLP) gradients at the central part of the polar low (Figure 2(d)) were expected to be visible. Therefore, it is not unlikely that the ECMWF analysis underestimates the intensity of the polar low by several $\mathrm{hPa}$ at this time. Since the 1000-500 hPa thickness field has weak gradients throughout the domain, we suggest that by now the polar low develops inside the Arctic air masses, and the absence of the strong gradients of thickness gradients so clearly evident at previous times (Figure 3(c) and $(d)$ ) suggests that baroclinic energy conversion is no longer important.

Further development shows that the polar low diminished in size (Figure 2(e)). However, spiral-like clouds are evident surrounding a clear but smaller eye seen at about $73^{\circ} \mathrm{N}, 51^{\circ} \mathrm{E}$. Similar to the above observations, the MSLP suggests that the ECMWF analysis places the weaker polar low $(970 \mathrm{hPa})$ too far south. The weak MSLP gradients at the central part of the simulated polar low suggest that the model underestimates the polar-low intensity at this time.

The satellite image valid at 0728 UTC on 21 December shows that the polar low is decaying west of Novaya Zemlya at approximately $72^{\circ} \mathrm{N}, 50^{\circ} \mathrm{E}$ (Figure $2(\mathrm{f})$ ). The $0600 \mathrm{UTC}$ analysis clearly underestimates the low $(985 \mathrm{hPa})$ as it makes landfall east of the observed low at this time. The $500 \mathrm{hPa}$ height shows that as this takes place, the upper-level low diminishes and moves east of Novaya Zemlya $\left(75^{\circ} \mathrm{N}, 60^{\circ} \mathrm{E}\right.$, Figure 3(f)). Later in this day at about 1100 UTC, satellite images show that the remnants of the polar low make landfall close to the southern tip of Novaya Zemlya about 5 hours later than in the ECMWF analysis (not shown).

\section{Evolution of the polar low in the control experiment}

In this section, we analyse the CTL experiment. As the synoptic-scale low $(972 \mathrm{hPa})$ enters the Barents Sea, the highest surface wind speeds (about $20 \mathrm{~m} \mathrm{~s}^{-1}$ ) are found on the cold side north of $73^{\circ} \mathrm{N}$ (Figure 4(a)). Twelve hours 

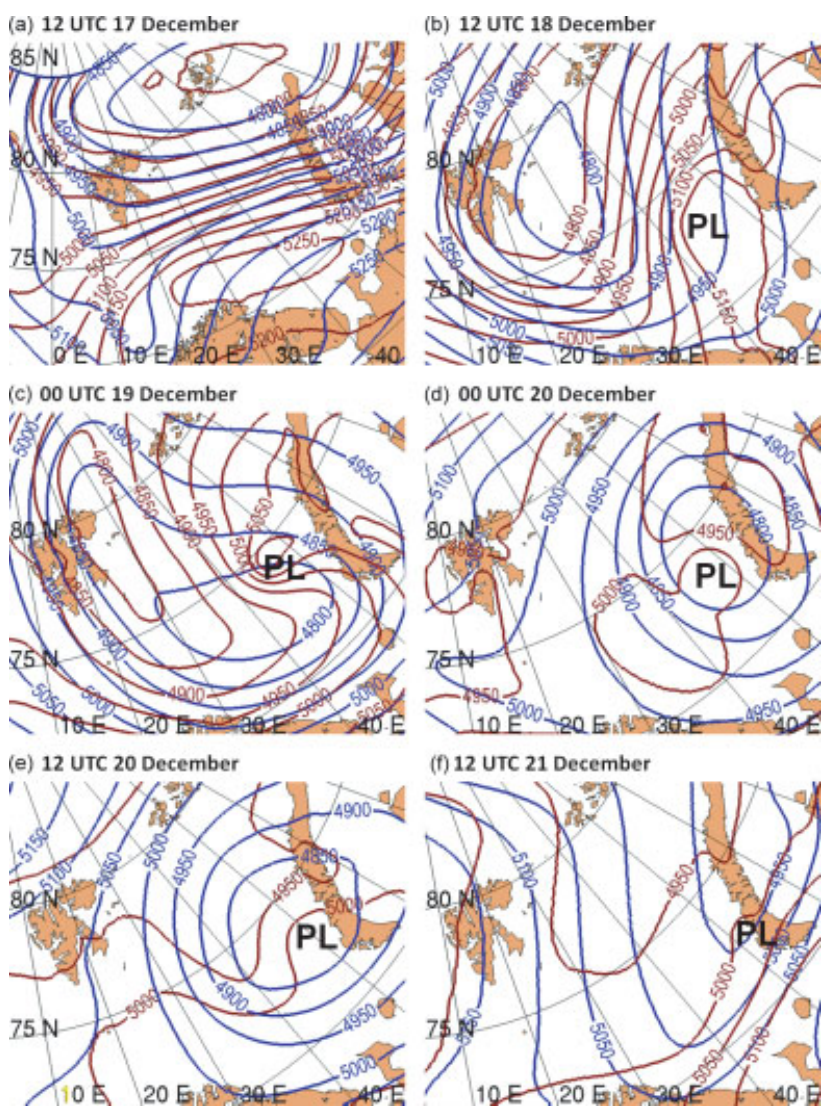

(d) 00 UTC 20 December

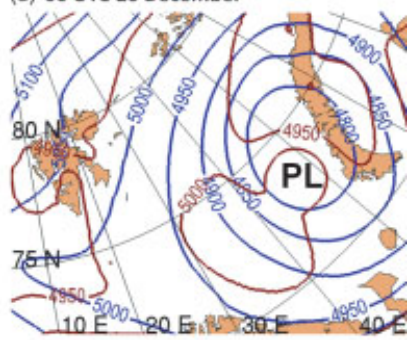

(f) 12 UTC 21 December

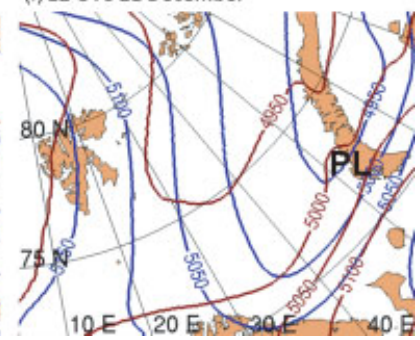

Figure 3. Height of the $500 \mathrm{hPa}$ surface from the ECMWF analysis (in metres, blue contours) and $500-1000 \mathrm{hPa}$ thickness (in metres, brown contours) for (a) 1200 UTC 17 December 2002; (b) 1200 UTC 18 December (c) 0000 UTC 19 December; (d) 0000 UTC 20 December; (e) 1200 UTC 20 December; and (f) 1200 UTC 21 December. The black capital letters PL show the approximate central position of the polar low.

later, the synoptic-scale low has deepened $(970 \mathrm{hPa})$ and is seen at about $72^{\circ} \mathrm{N}, 41^{\circ} \mathrm{E}$, with surface wind speed reaching up to $25 \mathrm{~m} \mathrm{~s}^{-1}$ west of the low (Figure 4(b)). The high vertical velocity seen at about $74^{\circ} \mathrm{N}, 48^{\circ} \mathrm{E}$ (Figure $5(\mathrm{~b})$ ) indicates an area of condensational heating. According to the satellite images, the simulated polar low develops northeast of the observed polar low $\left(74^{\circ} \mathrm{N}, 45^{\circ} \mathrm{E}\right)$. The 1000-500 hPa thickness shows that as a result of the cyclonic flow of the synoptic low (Figure 4(a) and (b)), a baroclinic zone separating relatively warm sub-polar air and Arctic air develops over the Barents Sea (Figure 5(a) and (b)) with an outbreak of Arctic air masses west of the developing polar low (Figure 4(b)).

At 0000 UTC on 19 December, a polar low with an eye-like structure and closed isobars centred at $74^{\circ} \mathrm{N}, 47^{\circ} \mathrm{E}$ is seen (Figure 4(c)). At surface level, the developing eye consists of calm $\left(<5 \mathrm{~m} \mathrm{~s}^{-1}\right)$ and relatively warm $\left(-4^{\circ} \mathrm{C}\right)$ air surrounded by colder air masses. Maximum wind speeds of about $25 \mathrm{~m} \mathrm{~s}^{-1}$ are seen in the eye wall. At this time, the polar-low position and baroclinic structure (Figure 5(c)) are similar to the ECMWF analyses (Figure 3(c)). Thus, baroclinic energy conversion is most likely an important physical mechanism in the early stages of the development. The roughly parallel lines of vertical velocity seen in the cold air outbreak to the west of the low indicate shallow moist convection (Figure 5(c)) that is consistent with the convective cloud bands seen in the satellite images (Figure 2(c)).

By 1200 UTC on 19 December, the simulated polar low had a pronounced hurricane-like appearance with a clear, calm, warm eye located at $74^{\circ} \mathrm{N}, 47^{\circ} \mathrm{E}$, circular isobars, and the highest surface wind speeds $\left(\sim 20 \mathrm{~m} \mathrm{~s}^{-1}\right)$ in the eye wall (Figure $4(\mathrm{~d})$ ). At this time, surface wind speeds had decreased, particularly west and south of the polar low, despite its deepening $(961 \mathrm{hPa})$. By now, the weaker gradients of 1000-500 hPa thickness suggest that baroclinic forcing has weakened (Figure 5(c) and (d)), which may explain the weaker surface wind speed. This observation is in agreement with the ECMWF analyses (Figure 3). The high vertical velocities seen close to the core of the low coincide with areas of strong condensational heating (not shown) indicating that condensational heating may be an important forcing mechanism (Figure 5(c) and (d)).

Twelve hours later, the polar low has moved southwest as it weakened to $966 \mathrm{hPa}$ (Figure 4(e)). A distinct eye is still present, centred at about $73^{\circ} \mathrm{N}, 44^{\circ} \mathrm{E}$, but according to the satellite images the simulated polar low is located about $4^{\circ}$ too far west. Despite the weakening of the polar low, the surface wind speed at the western side of the eye has increased $\left(\sim 25 \mathrm{~m} \mathrm{~s}^{-1}\right)$. According to scatterometer winds (not shown) the control experiment successfully simulated the wind speed west of the low, but east of the low the wind speed is underestimated (Figure 4(e)). It should be kept in mind that scatterometer winds are often overestimated over the high-latitude oceans, especially at high surface wind speed (Renfrew et al., 2009). The spiral-like vertical velocity bands ending at the eye of the polar low (Figure 5(e)) show a structure similar to the cloud bands in the satellite images (Figure 3(d)). Consistent with the ECMWF analyses, the absence of a baroclinic zone (Figure 5(e)) and the evidence of a strong cold air outbreak suggest that surface energy fluxes may be essential in the development at this time (see section 5).

At 1200 UTC on 20 December, the MSLP shows that the polar low made landfall at about $72^{\circ} \mathrm{N}, 52^{\circ} \mathrm{E}$ (Figure $4(\mathrm{f}$ )). Although the behaviour of the simulated low did not exactly duplicate that of the observed low, the two systems had enough features in common by 0000 UTC on 20 December to regard the modelled low as representative of the observed system up to this time. This assumption is the basis for the analysis that we now present.

\subsection{Surface energy fluxes}

In Figure 6, simulated surface sensible heat (SH) fluxes are shown in the left column and latent heat (LH) fluxes in the right column, both for the CTL experiment. The magnitude of the simulated surface energy fluxes is controlled by roughness length, surface wind speed, relative humidity, and air-sea temperature differences (Chen and Dudhia, 2001).

In the early stages of the polar-low development, high surface wind speed and strong cold air outbreak of Arctic air masses west of the polar low (Figure 4(c)) trigger extreme surface fluxes. At the western side of the developing eye, maximum SH fluxes are about $1200 \mathrm{~W} \mathrm{~m}^{-2}$ while the $\mathrm{LH}$ fluxes are about $400 \mathrm{~W} \mathrm{~m}^{-2}$ (Figure 6(a) and (b)). Similar conditions explain the high surface energy fluxes (1400 and $500 \mathrm{~W} \mathrm{~m}^{-2}$, respectively) seen farther west downwind of the sea ice edge $\left(74-76^{\circ} \mathrm{N}\right)$. The small area of almost no surface energy fluxes centred at about $74^{\circ} \mathrm{N}, 47^{\circ} \mathrm{E}$ marks the calm and relatively warm developing eye of the polar low (Figure 6(a) and (b)). 
(a) 00 UTC 18 December

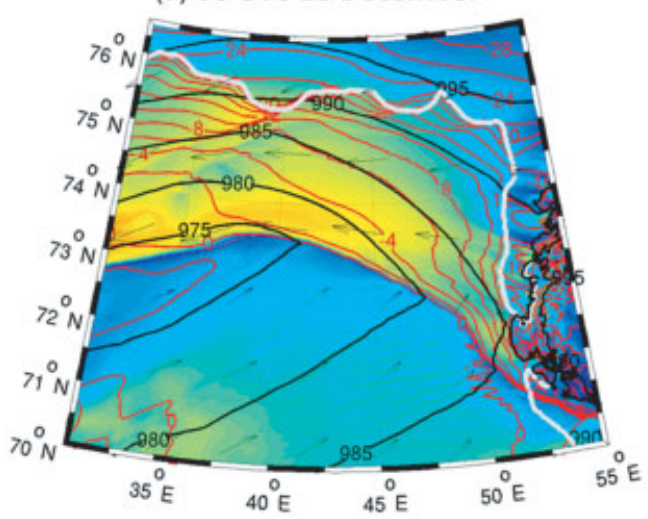

(c) 00 UTC 19 December

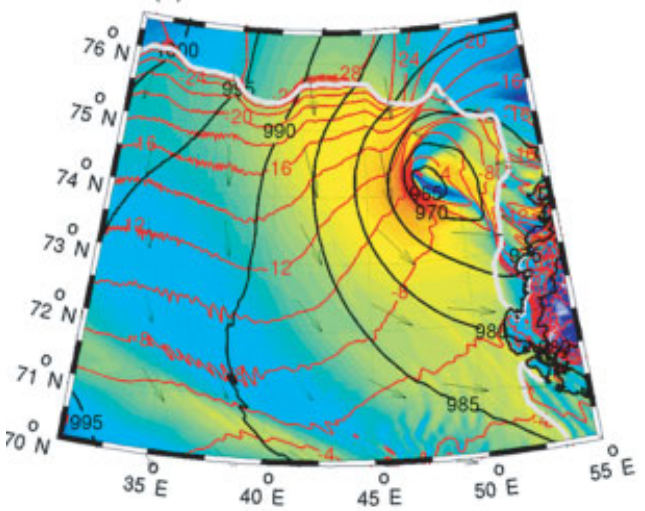

(e) 00 UTC 20 December

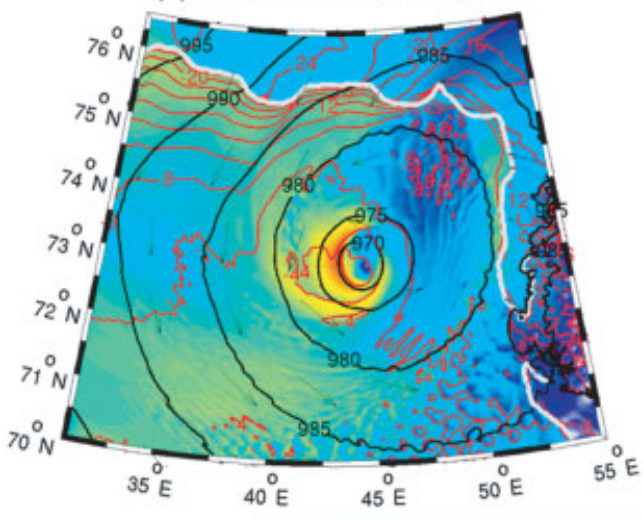

(b) 12 UTC 18 December

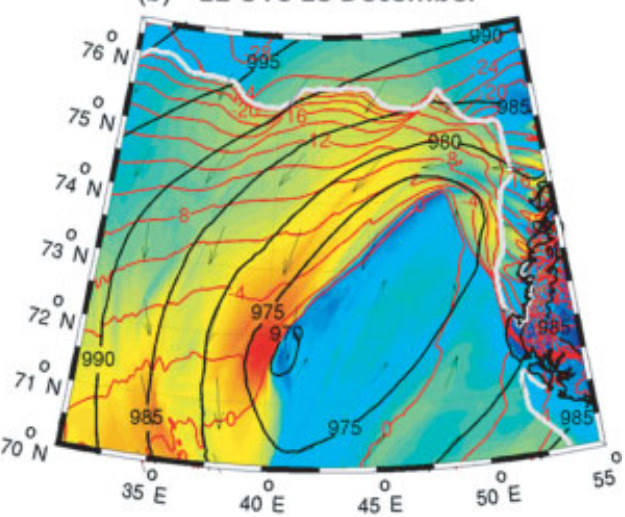

(d) 12 UTC 19 December

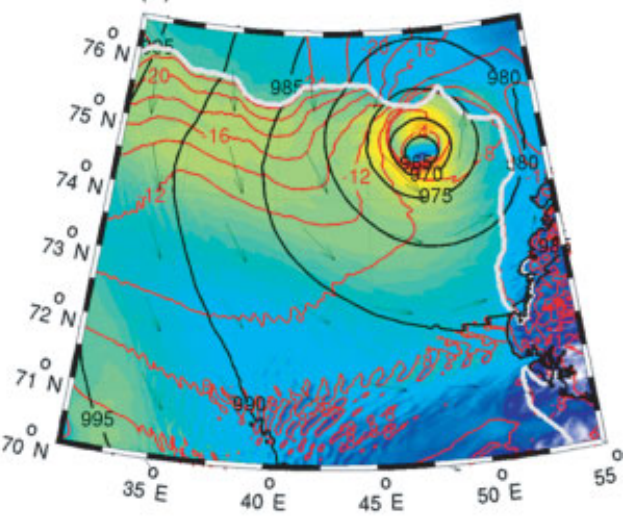

(f) 12 UTC 20 December

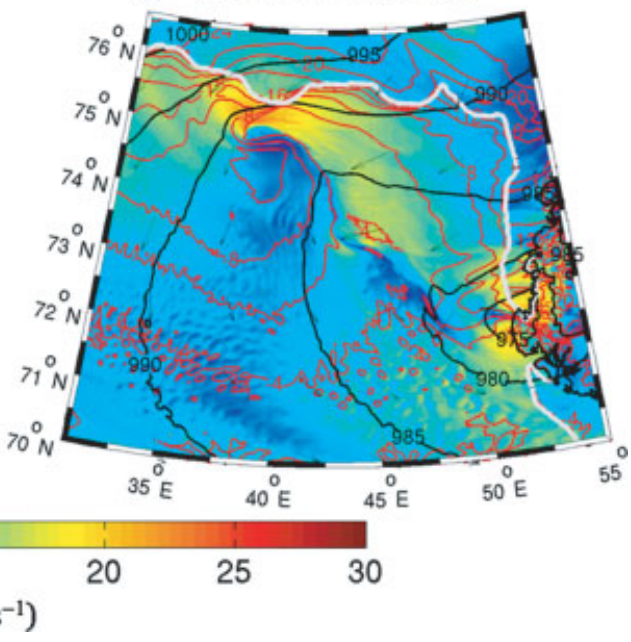

Figure 4. Mean-sea-level pressure (MSLP, black contours, $\mathrm{hPa})$, temperature at $2 \mathrm{~m}\left(2^{\circ} \mathrm{C}\right.$ interval, red contours), and $10 \mathrm{~m}$ wind speed (in $\mathrm{m} \mathrm{s}{ }^{-1}$, colour shading) from the CTL experiment. Black arrows show $10 \mathrm{~m}$ wind direction. The sea ice edge is shown with a thick, white curve. The following times are shown: (a) 0000 UTC 18 December 2002; (b) 1200 UTC 18 December; (c) 0000 UTC 19 December; (d) 1200 UTC 19 December; (e) 0000 UTC 20 December; and (f) 1200 UTC 20 December.

At 1200 UTC on 19 December, the pronounced warm and calm eye $\left(74^{\circ} \mathrm{N}, 47^{\circ} \mathrm{E}\right)$ of the polar low (e.g. see Figure $\left.4(\mathrm{~d})\right)$ is clearly evident with negligible $\mathrm{SH}$ and LH fluxes (Figure 6(c) and (d)). Maximum SH and LH fluxes at the eye wall have slightly weakened to about $1000 \mathrm{~W} \mathrm{~m}^{-2}$ and $350 \mathrm{~W} \mathrm{~m}^{-2}$, respectively. The drop in surface wind speed during the preceding 12 hours (Figure 4(c) and (d), respectively) most likely explains the lower surface energy fluxes. The increase in surface energy fluxes seen west of the polar low, between $30^{\circ} \mathrm{E}$ and $35^{\circ} \mathrm{E}$, is probably explained by the slightly higher surface wind speed in this area (Figure $4(\mathrm{~d})$ ).
Twelve hours later, despite increased surface wind speed at the western side of the eye wall (Figure 4(d) and (e)), maximum $\mathrm{SH}$ and $\mathrm{LH}$ fluxes have now weakened to about $600 \mathrm{~W} \mathrm{~m}^{-2}$ and $300 \mathrm{~W} \mathrm{~m}^{-2}$, respectively (Figure 6(e) and (f)). The reduction in surface fluxes of heat and moisture is probably explained by reduced air-sea temperature differences. As the distance from the sea ice edge has increased, air masses are further warmed (Figure 4(d) and (e)) by the extreme $\mathrm{SH}$ fluxes before reaching the polar low. This effect results in reduced air-sea temperature differences and thus a drop in surface energy fluxes. The area of low surface energy fluxes east of the polar low is most likely 
(a) 00 UTC 18 December

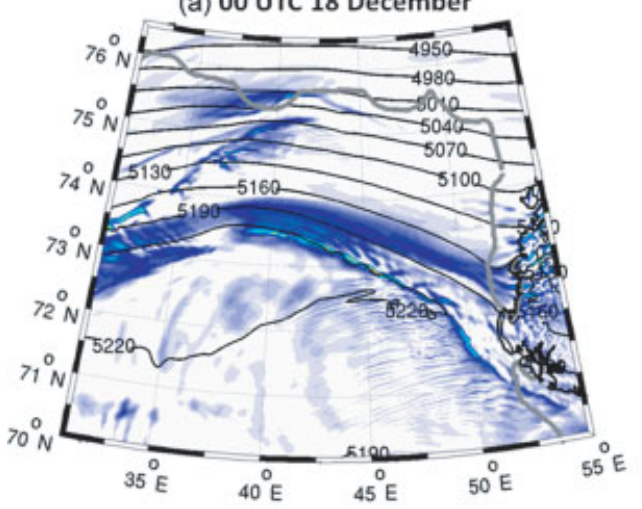

(c) 00 UTC 19 December

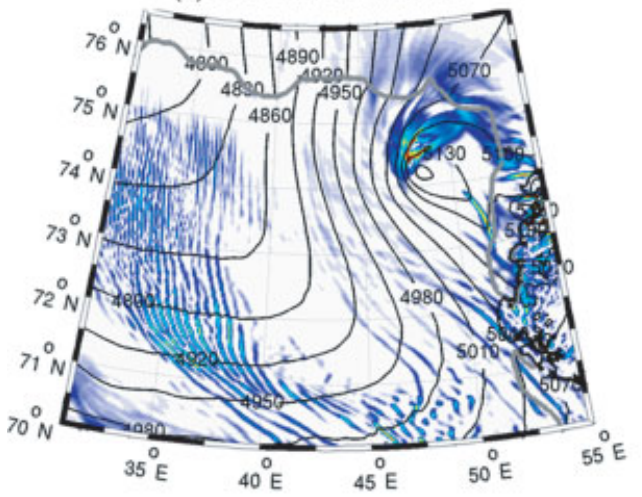

(e) 00 UTC 20 December

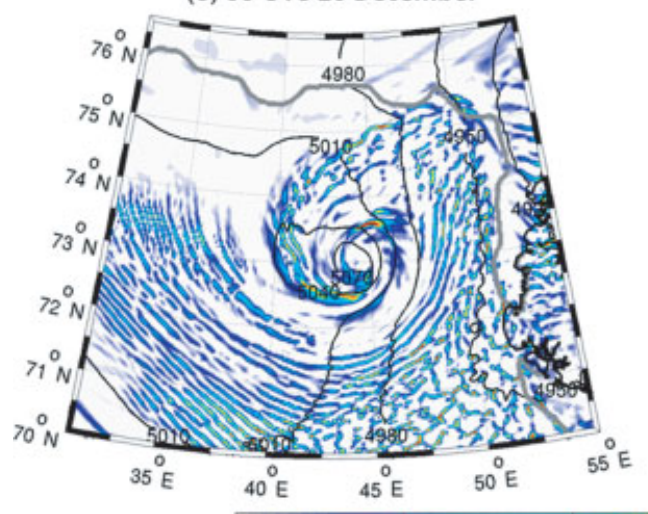

(b) 12 UTC 18 December

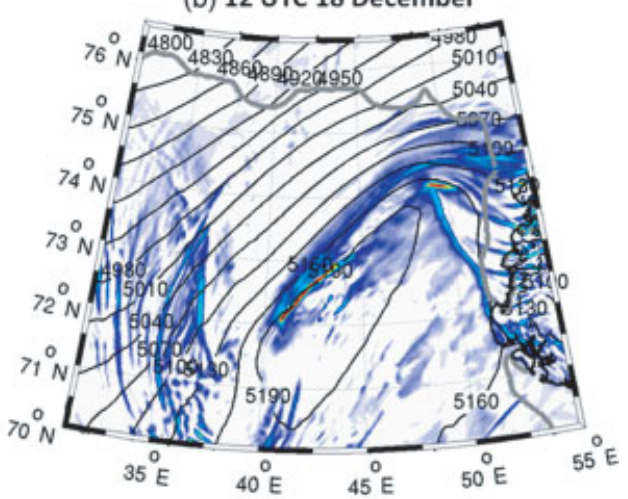

(d) 12 UTC 19 December

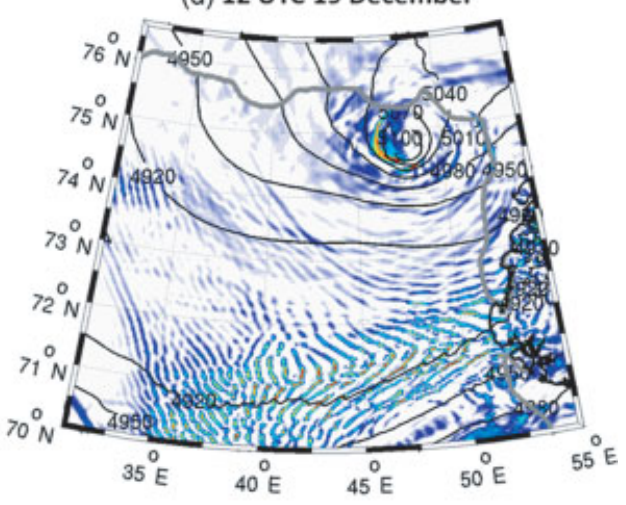

(f) 12 UTC 20 December

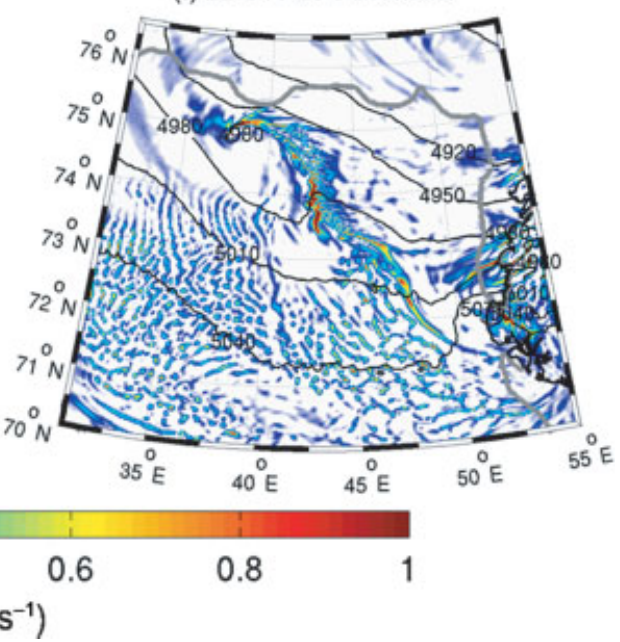

Figure 5. Vertical wind speed ( $\mathrm{m} \mathrm{s}^{-1}$, colour shading) at $850 \mathrm{hPa}$ surface and 500-1000 hPa thickness (40 m interval, black contours) from the CTL experiment. The sea ice edge is shown with a thick grey curve. (a) 0000 UTC 18 December 2002; (b) 1200 UTC 18 December; (c) 0000 UTC 19 December; (d) 1200 UTC 19 December; (e) 0000 UTC 20 December; and (f) 1200 UTC 20 December.

caused by the strong reduction in surface wind speed in this area (Figure $4(\mathrm{e})$ ).

According to Liu et al. (2006), the updraught- and downdraught-induced circulations set up by the development of cloud streets influence the spatial distribution of surface energy fluxes. Below the cloud streets (Figure 5(e)), surface energy fluxes are suppressed (Figure 6(e) and (f)). The increased flux between the cloud streets is caused by a downdraught of relatively dry air (not shown here) resulting in higher surface wind speed (Liu et al., 2006). Figure 4(e) shows traces of lines of high and low surface wind speeds south and west of the polar low, which correlate with the simulated bands of high vertical velocities (i.e. cloud streets) in the same area (Figure 5(e)).
The relative magnitude of surface energy fluxes in our simulations is very different from that in hurricanes, which typically have SH fluxes of $150-200 \mathrm{~W} \mathrm{~m}^{-2}$ and maximum LH fluxes of about $1000 \mathrm{~W} \mathrm{~m}^{-2}$ (Trenberth and Fasullo, 2008). However, the surface energy fluxes obtained in this study are consistent with previous numerical simulations of surface energy fluxes close to the sea ice edge. Bresch et al. (1997) studied an intense polar low close to the sea ice edge over the western Bering Sea with the MM5 model. Their simulations indicated maximum $\mathrm{SH}$ fluxes of $1000 \mathrm{~W} \mathrm{~m}^{-2}$ and $\mathrm{LH}$ fluxes of $300 \mathrm{~W} \mathrm{~m}^{-2}$. In a numerical study of an Arctic front near Bjørnøya (Bear Island near Svalbard), for which measurements from a coastguard ship indicated winds in excess of hurricane force, Grønås and 
(a) 00 UTC 19 December

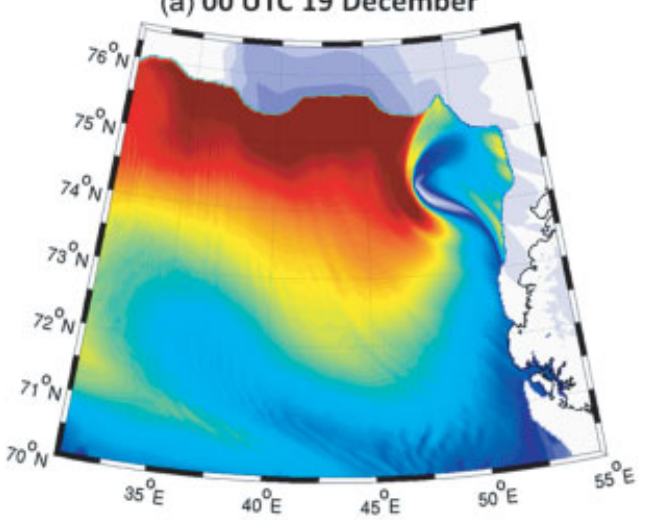

(c) 12 UTC 19 December

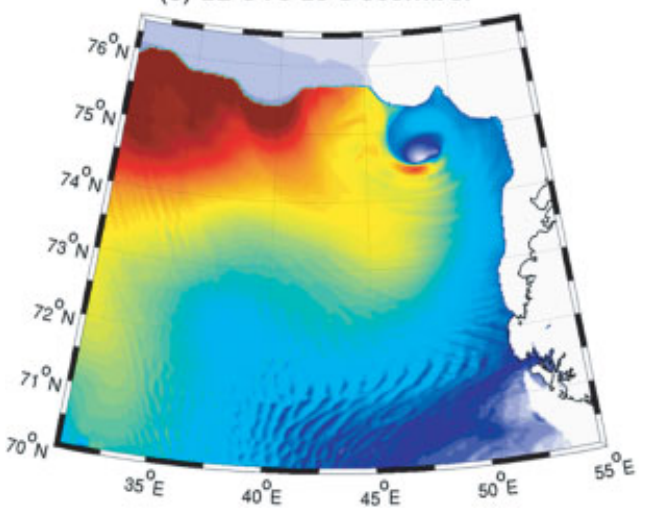

(e) 00 UTC 20 December

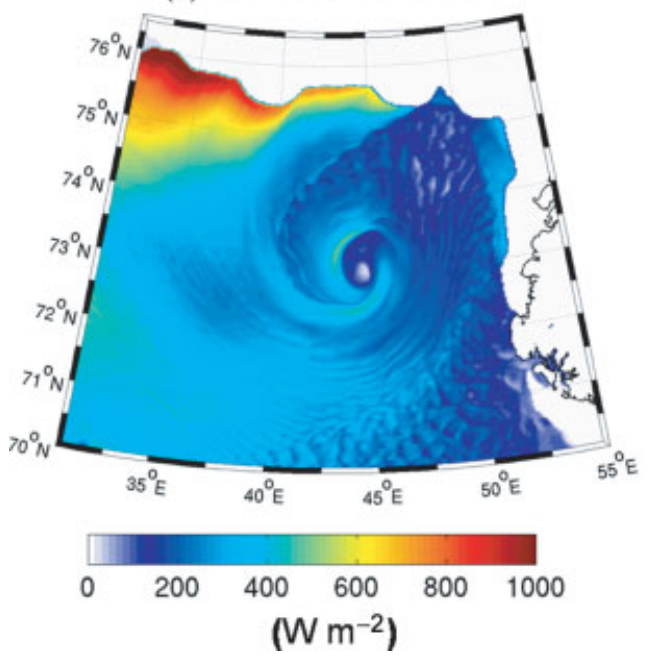

(b) 00 UTC 19 December

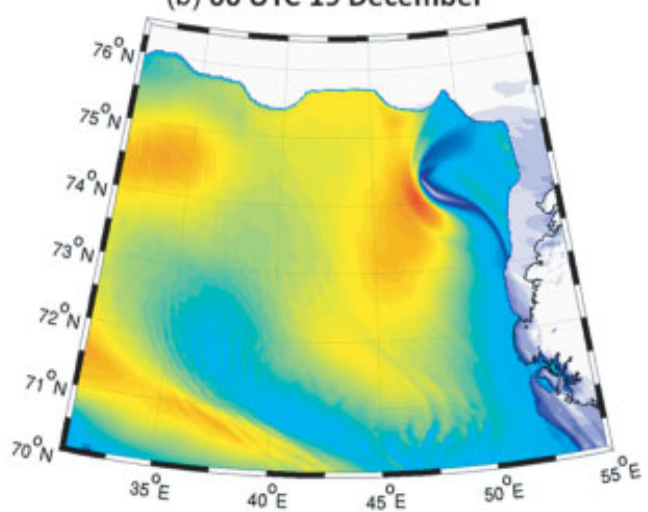

(d) 12 UTC 19 December

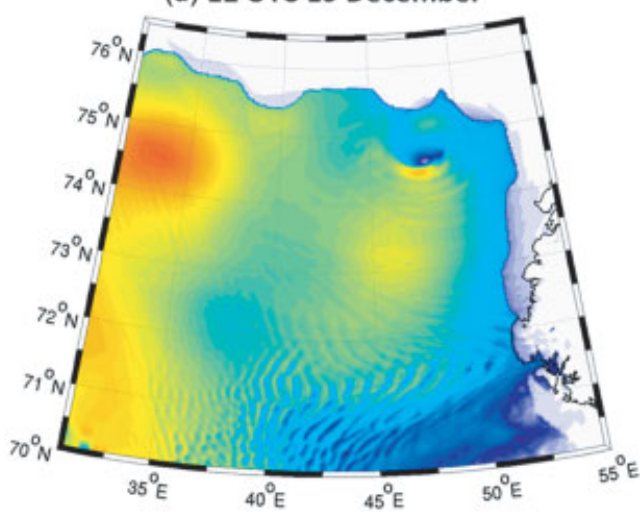

(f) 00 UTC 20 December

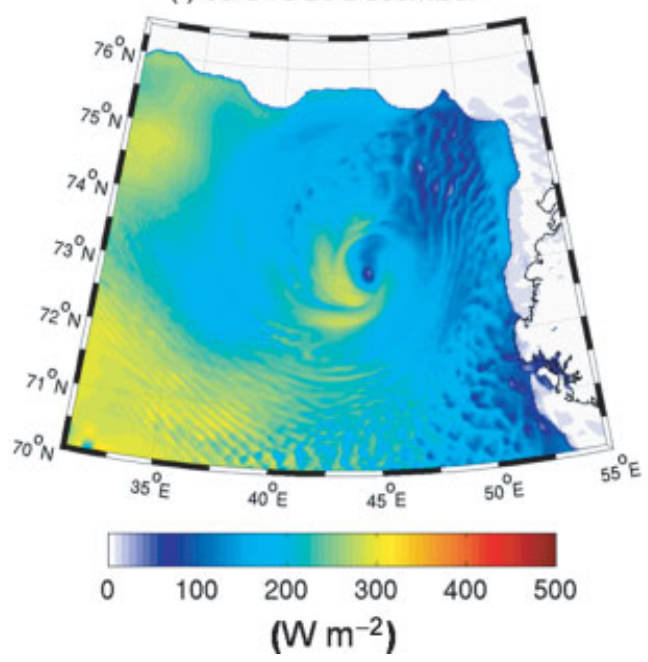

Figure 6. Surface sensible heat (left column) and latent heat (right column) fluxes $\left(\mathrm{W} \mathrm{m}^{-2}\right)$ from the CTL experiment. The sea ice and land masses are seen as areas of almost zero fluxes. (a), (b) 0000 UTC 19 December 2002; (c), (d) 1200 UTC 19 December; and (e), (f) 0000 UTC 20 December. Note the difference in scale between sensible heat (left column) and latent heat (right column) fluxes.

Skeie (1999) found $\mathrm{SH}$ fluxes of $1300 \mathrm{~W} \mathrm{~m}^{-2}$ in their simulations. These values were matched in the numerical polar-low study of Mailhot et al. (1996), who found SH fluxes of $1400 \mathrm{~W} \mathrm{~m}^{-2}$ near the edge of the sea ice. The weaker surface fluxes seen in later stages of the simulated polar low are consistent with a numerical case-study by Nordeng and Rasmussen (1992) of a hurricane-like polar low that flared up within an old occlusion over the Norwegian Sea. During that polar-low event, $\mathrm{SH}$ fluxes of about $500 \mathrm{~W} \mathrm{~m}^{-2}$ and LH fluxes of about $250 \mathrm{~W} \mathrm{~m}^{-2}$ were simulated. As discussed in section 5, the extremely high $\mathrm{SH}$ fluxes in our case inevitably influence the simulated behaviour of the polar low, including its sensitivity to both surface energy fluxes and condensational heating.

\subsection{Control experiment through a PV perspective}

In this subsection, the polar-low development is analysed through the PV paradigm originally developed for cyclogenesis by Hoskins et al. (1985) and adjusted to polar lows by Montgomery and Farrell (1992).

In Figure 7(a), PV and 500 hPa heights at 1200 UTC on 18 December are shown along with MSLP for the CTL experiment. A strong (3-4 PV unit (PVU)) upper-level PV 
(a) 12 UTC 18 December

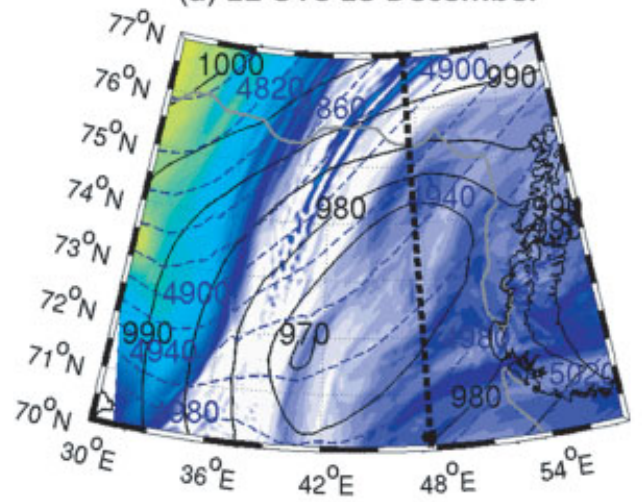

(c) 00 UTC 19 December

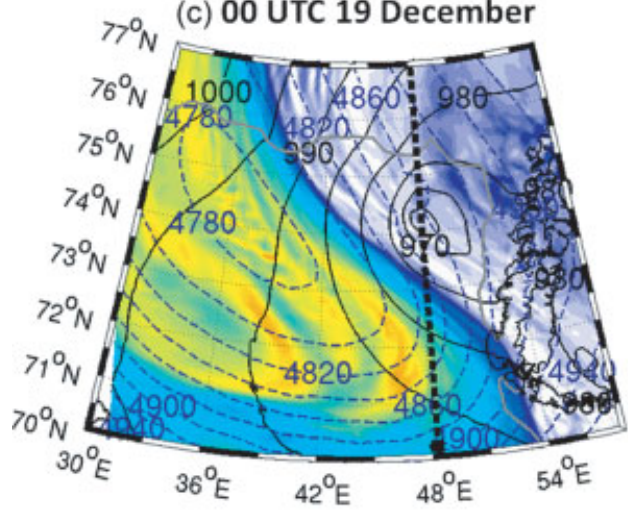

(e) 12 UTC 19 December

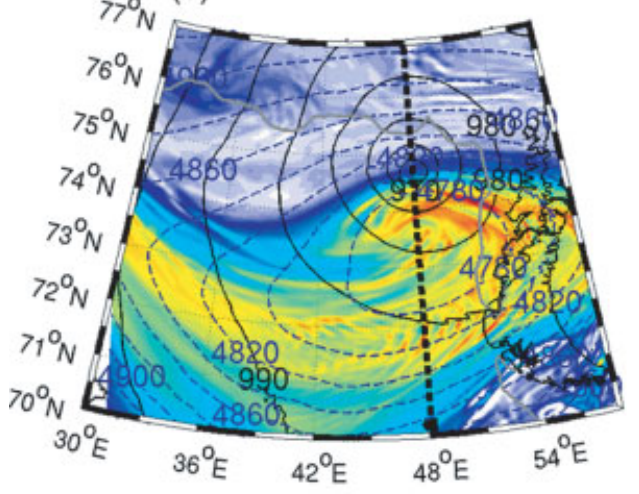

(b) 12 UTC 18 December

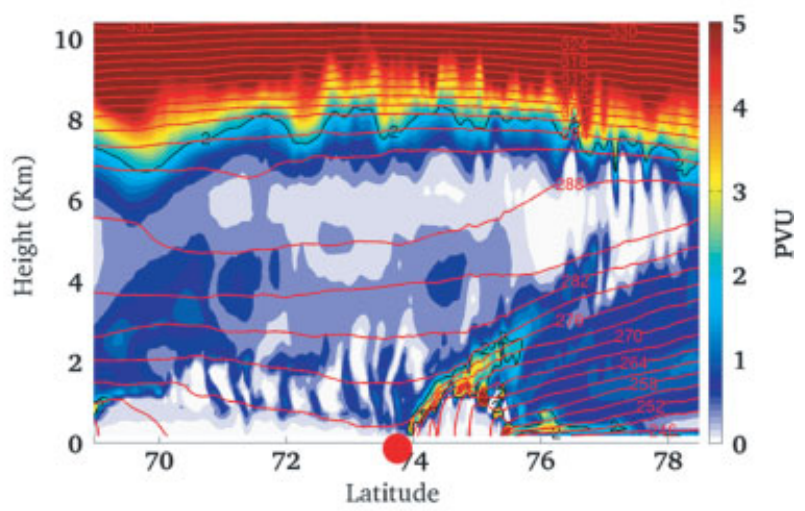

(d) 00 UTC 19 December

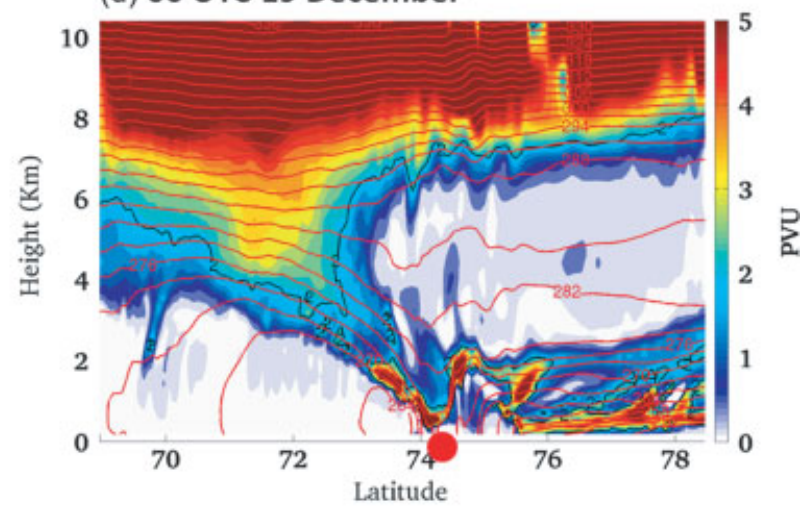

(f) 12 UTC 19 December

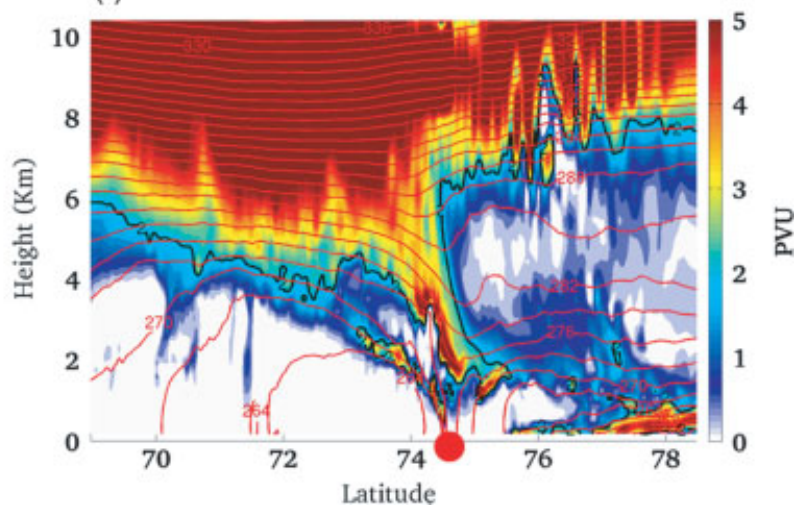

Figure 7. Left column: Potential vorticity (colour shading) and geopotential height (blue contours, $40 \mathrm{~m}$ interval) at $500 \mathrm{hPa}$ and sea-level pressure ( $5 \mathrm{hPa}$ black contours) from the CTL experiment. The black dotted line shows position of cross-section to the right. The sea ice edge is shown with a grey curve. Right column: Cross-section of PV and potential temperature from the CTL experiment. $1 \mathrm{PVU}$ unit is equivalent to SI units $1 \times 10^{-6} \mathrm{~m}^{2} \mathrm{~s}^{-1} \mathrm{~K} \mathrm{~kg}^{-1}$. (a), (b) 1200 UTC 18 December 2002; (c), (d) 0000 UTC 19 December; and (e), (f) 1200 UTC 19 December. Red dots mark the polar-low positions.

(UPV) anomaly seen on the western side of the figure is related to the upper-level low shown in Figure 3(b).

South of the developing polar low, the constant potential temperature seen in the cross-section of PV and potential temperature shows (Figure 7(b)) a well-mixed atmosphere with weak static stability up to the tropopause (2 PVU, $\sim 8 \mathrm{~km})$. The cross-section cuts through the area where our polar low develops during the next 12 hours. Over the sea ice north of $75.3^{\circ} \mathrm{N}$, the strong vertical gradient of potential temperature shows stable Arctic air masses below the height of $4 \mathrm{~km}$. The low-level PV (LPV) anomaly at about $500-2000 \mathrm{~m}$ height, located between $74^{\circ} \mathrm{N}$ and $76^{\circ} \mathrm{N}$, is most likely caused by condensational heating (Figure 5(b)) and is believed to be a signature of the developing polar low.

At 0000 UTC on 19 December, the UPV anomaly has moved southeast and is seen centred at $74.5^{\circ} \mathrm{N}, 36^{\circ} \mathrm{E}$
(Figure 7(c)). Figure 7(d) shows a stratospheric downfolding of high PV values (2-5 PVU) between $71^{\circ} \mathrm{N}$ and $73^{\circ} \mathrm{N}$ reaching down to about $4 \mathrm{~km}$ height. A warm surface potential temperature $(\theta)$ anomaly and a strong (2-5 PVU) LPV anomaly confined below $2 \mathrm{~km}$ height are centred at the polar-low eye $\left(74.2^{\circ} \mathrm{N}\right)$. At this time, a north-south phase tilt of high PV air (1-2 PVU) is seen between the polar low and the UPV anomaly. The high PV values (1-5 PVU) below $1 \mathrm{~km}$ height over the sea ice $\left(>75.4^{\circ} \mathrm{N}\right)$ indicate very stable Arctic masses.

Twelve hours later, the UPV anomaly has intensified as it moved east and is now located south of the polar low. Condensational heating appears to erode the upper-level PV anomaly and prevent it from becoming vertically aligned with the surface polar low (Plant et al., 2003; Bracegirdle and Gray, 2009). As a result, the polar low is placed below 


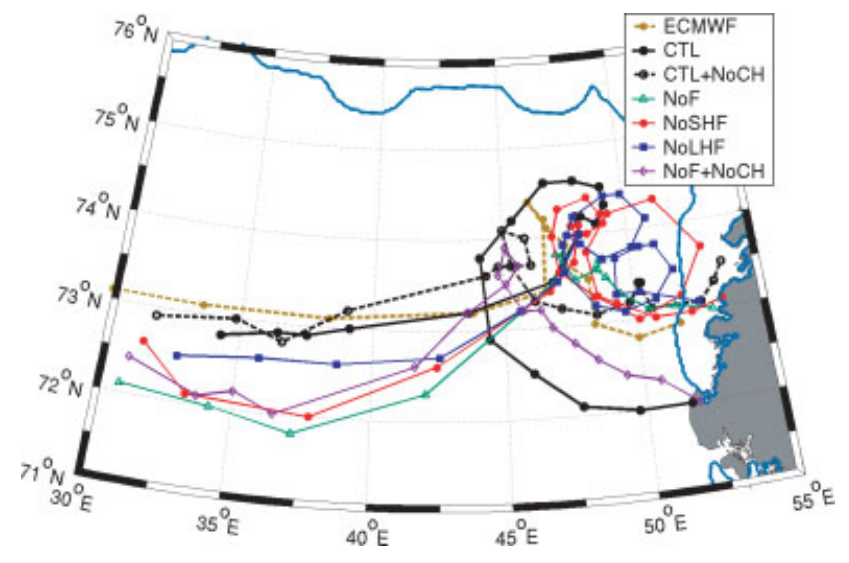

Figure 8. Tracks of minimum centred surface pressure at 3-hour intervals for each model experiment listed in Table 1. The track starts at 0000 UTC 18 December 2002 and ends when the polar low makes landfall. The sea ice edge is marked with a blue curve. ECMWF (dashed brown), CTL (black), $\mathrm{CTL}+\mathrm{NoCH}$ (dashed black), NoF (green), NoSHF (red), NoLHF (blue), and $\mathrm{NoF}+\mathrm{NoCH}$ (purple).

the outer edge of the UPV anomaly (Figure 7(e)). As the UPV anomaly moves eastward (Figure 7(c) and (e)), the polar low is steered by the upper-level cyclonic flow set up by the UPV anomaly (not shown here), explaining the polar low's northward track (Figure 7(c) and (e)).

The cross-section now shows a wider and more intense UPV anomaly (Figure 7(f)). The high PV air (2-5 PVU, Figure 7(f) ) seen in the phase tilt between the UPV anomaly and the polar low, at about $2-3 \mathrm{~km}$ height, is not believed to be a sign of stratospheric downfolding but is most likely caused by strong condensational heating at the eye wall (Figure 5(d)). A slightly weaker $\theta$ anomaly is centred at the polar low eye $\left(74.2^{\circ} \mathrm{N}\right)$. The strong gradients of potential temperature seen above the surface mark the top of the PBL. On top of the PBL $(\sim 2 \mathrm{~km})$, centred at the polar-low core, a strong (2-5 PVU) LPV anomaly is seen. The air over the ice $\left(>75.3^{\circ} \mathrm{N}\right)$ is now less stable than before because during the last 12 hours, the southerly flow of modified air masses east of the polar low (Figure $4(\mathrm{c})$ and $(\mathrm{d})$ ) has led to less stable air over the sea ice $\left(>75.3^{\circ} \mathrm{N}\right)$.

The model diagnostic cannot completely clarify the exact coupling mechanisms. However, based on the above discussion, we note that the polar-low development fits well with the conceptual model of polar-low cyclogenesis by Montgomery and Farrell (1992) and Grønås and Kvamstø (1995). In short, the UPV anomaly sets up a $\theta$ anomaly (Figure 7(d) and (f)) that - through mutual interaction and phase-locking with the UPV anomaly - was able to form a significant low-level circulation (e.g. see Figure 4(c) and (e)) and create an LPV anomaly (Figure 7(d) and (f)) by condensational heating in organized convection (e.g. see Figure 5(c) and (d)). Condensational heating maintained a phase tilt between the polar low and the UPV anomaly by destruction of PV aloft. The PV thus produced then contributed to the low-level circulation, further intensifying the polar low (Figure 4(c) and (d)). The intensifying UPV anomaly and increased PV values seen in the phase tilt are viewed as evidence of a phase lock and mutual intensification between the UPV anomaly and the polar low (Figure 7(d) and (f)). It should be mentioned that evidence of a phase lock between the UPV anomaly and the polar low persisted until the polar low made landfall (not shown), suggesting that upper-level PV forcing is important throughout the lifetime of the polar low. The role of upper-level PV forcing in later stages of polar-low developments is still not well understood. However, using PV inversion, both Wu et al. (2011) and Føre et al. (2011) demonstrated that, in some polar lows, upper-level PV forcing might be essential throughout the life cycle.

\section{Sensitivity experiments}

This section investigates the sensitivity of polar-low intensity to surface energy fluxes and condensational heating in order to clarify the underlying physical processes of the polar low. The rate of intensification of the polar low is described using plots of minimum central surface pressure as a function of time. As in the CTL experiment, most of the sensitivity experiments simulated the polar-low track successfully up to early 20 December, but most predicted landfall about 24 hours too early according to satellite observations (Figure 2). Only experiments removing sensible heat (NoSHF) or latent heat (NoLHF) fluxes accurately reproduced the time of landfall at Novaya Zemlya. Thus, our conclusions will be based on the period from 0000 UTC 18 December to 0000 UTC 20 December.

By comparing experiments in which condensational heating was turned off throughout the simulation with their counterparts (CTL, CTL+NoCV, WSM6, WSM6+NoCV versus $\mathrm{CTL}+\mathrm{NoCH}, \mathrm{CTL}+\mathrm{NoCv}+\mathrm{NoCH}$, WSM6+NoCH, WSM6+NoCv+NoCH, Table 1), a distinct difference in track and polar-low intensity was observed (see the text below). For this reason, only the CTL and the CTL+NoCH, as well as the CTL+NoCH-D experiments, will be presented in the discussion on the role of condensational heating (section 5.3).

Table 2 presents a brief summary of the effects of the various physical processes on polar-low intensity based on the result of each sensitivity experiment (Table 1).

\subsection{Simulated track and lifetime}

Figure 8 shows the tracks of the polar low (i.e. the location of minimum surface pressure every 3 hours) for the ECMWF analyses and some experiments listed in Table 1.

In the ECWMF analyses (brown, Figure 8), the polar low moves eastward along the $73^{\circ} \mathrm{N}$ latitude until early 19 December before it makes a turn northward and then makes landfall further south at about $73^{\circ} \mathrm{N}, 52^{\circ} \mathrm{E}$ at 0600 UTC on 21 December. In the CTL experiment, the polar low has a track similar to that observed in the ECMWF analyses up to about 1500 UTC on 18 December, but it makes a larger northward loop before landfall further south $\left(\sim 72^{\circ} \mathrm{N}, 52^{\circ} \mathrm{E}\right.$, Figure 8). All delayed (D) experiments show a track similar to the CTL experiment from 1200 UTC on 19 December and thereafter (not shown). When condensational heating was turned off (e.g. CTL+NoCH), the polar low made a smaller and more southerly loop than was seen in the CTL before landfall at about $73^{\circ} \mathrm{N}, 52^{\circ} \mathrm{E}$ (Figure 8) about 3 hours earlier. The removal of both surface energy fluxes $(\mathrm{NoF})$ produced a polar-low track similar to the CTL+NoCH, but the polar low made landfall farther south (Figure 8). When sensible heat fluxes (NoSHF) and latent heat fluxes (NoLHF) are turned off, the polar low makes two northward loops farther south and east than in the CTL experiment, and both experiments show a polar-low lifetime similar to the ECMWF analyses (Figure 8). 
Table 2. A brief summary of the effect of various physical processes on the polar-low intensity based on the results of each sensitivity experiments.

\begin{tabular}{|c|c|}
\hline Abbreviation & Results \\
\hline CTL & $\begin{array}{l}\text { The polar-low deepening stage is a result } \\
\text { of baroclinic instability interacting with an } \\
\text { upper-level PV anomaly. }\end{array}$ \\
\hline $\mathrm{CTL}+\mathrm{NoCH}$ & $\begin{array}{l}\text { Condensational heating plays a minor role } \\
\text { during the polar-low deepening stage but has } \\
\text { a negative role on the polar-low intensity } \\
\text { thereafter. }\end{array}$ \\
\hline $\mathrm{CTL}+\mathrm{NoCH}-\mathrm{D}$ & $\begin{array}{l}\text { Condensational heating plays a minor role } \\
\text { in the polar-low intensity after its deepening } \\
\text { stage. }\end{array}$ \\
\hline $\mathrm{CTL}+\mathrm{NoCv}$ & $\begin{array}{l}\text { The polar-low intensity is rather unaffected } \\
\text { by the treatment of convection in the model. }\end{array}$ \\
\hline $\mathrm{CTL}+\mathrm{NoCv}+\mathrm{NoCH}$ & $\begin{array}{l}\text { Condensational heating plays a minor role } \\
\text { during the polar-low deepening stage but has } \\
\text { a negative effect on the polar-low intensity } \\
\text { thereafter. }\end{array}$ \\
\hline WSM6 & $\begin{array}{l}\text { The polar-low intensity is rather unaffected } \\
\text { by the treatment of cloud microphysical } \\
\text { processes in the model. }\end{array}$ \\
\hline WSM6+NoCH & $\begin{array}{l}\text { Condensational heating plays a minor role } \\
\text { during the polar-low deepening stage but } \\
\text { has a negative role in the polar-low intensity } \\
\text { thereafter. }\end{array}$ \\
\hline WSM6+NoCH-D & $\begin{array}{l}\text { Condensational heating plays a minor role } \\
\text { in the polar-low intensity after its deepening } \\
\text { stage. }\end{array}$ \\
\hline WSM6+NoCv & $\begin{array}{l}\text { The polar-low intensity is rather unaffected } \\
\text { by the treatment of convection in the model. }\end{array}$ \\
\hline WSM6+NoCv+NoCH & $\begin{array}{l}\text { Condensational heating plays a minor role } \\
\text { during the polar-low deepening stage but has } \\
\text { a negative role on the polar-low intensity } \\
\text { thereafter. }\end{array}$ \\
\hline $\mathrm{NoF}$ & $\begin{array}{l}\text { Surface energy fluxes play a minor role during } \\
\text { the polar-low deepening stage but become } \\
\text { gradually more important for the polar-low } \\
\text { intensity thereafter. }\end{array}$ \\
\hline NoF-D & $\begin{array}{l}\text { Surface energy fluxes are important for the } \\
\text { polar-low intensity. }\end{array}$ \\
\hline NoSHF & $\begin{array}{l}\text { Sensible heat fluxes play a minor role during } \\
\text { the polar-low deepening stage but become } \\
\text { gradually more important for the polar-low } \\
\text { intensity thereafter. }\end{array}$ \\
\hline NoSHF-D & $\begin{array}{l}\text { Sensible heat fluxes are important for the } \\
\text { polar-low intensity after its deepening stage. }\end{array}$ \\
\hline NoLHF & $\begin{array}{l}\text { Latent heat fluxes play a minor role during } \\
\text { the polar-low deepening stage and thereafter. }\end{array}$ \\
\hline NoLHF-D & $\begin{array}{l}\text { Latent heat fluxes are irrelevant for the polar- } \\
\text { low intensity after its deepening stage. }\end{array}$ \\
\hline $\mathrm{NoF}+\mathrm{NoCH}$ & $\begin{array}{l}\text { Dry baroclinic energy conversion is the } \\
\text { dominant forcing mechanism during the } \\
\text { polar-low deepening stage but vanishes } \\
\text { thereafter. }\end{array}$ \\
\hline
\end{tabular}

In order to explain the 24-hour-too-early landfall seen in the CTL we have carried out several numerical tests. In an experiment (not shown) where the number of vertical levels was reduced to 30 , with eight levels in the PBL, the polar low showed a similar track as in the CTL. In another experiment in which the sea ice was removed west of Novaya Zemlya (see Figure 1) the polar low had similar intensity and track as in the CTL. McInnes et al. (2011) showed that a polar low over the Norwegian Sea was sensitive to the initial conditions and starting time of the models runs. As discussed in section 2, differences in initial conditions and starting time did not improve the simulated time of landfall in the CTL. Subsection 5.3 addresses the differences in simulated polar-low track and lifetime in the different experiments. However, in order to understand the too early landfall in CTL, the role of upper-level PV forcing must be discussed.

\subsection{The role of surface energy fluxes}

In this subsection, we investigate the role of surface energy fluxes using the sensitivity experiments described in section 2 (Table 1).

In short, the CTL experiment and the ECMWF analyses (not shown) show a deepening of the polar low (approximately $9 \mathrm{hPa} \mathrm{day}^{-1}$ ) up to about 0900 UTC on 19 December (Figure 9). Until the end of the deepening period, at about 0600 UTC on 19 December, the polar-low intensity is not very sensitive to surface flux modifications (NoF, NoSHF, NoLHF, Figure 9). After this time, the simulated polar-low intensity is increasingly sensitive to the removal of sensible heat fluxes (NoSHF), but latent heat fluxes (NoLHF) seem to play a minor role (Figure 9). The importance of sensible heat fluxes is clearly seen by comparing the NoSHF experiment with the experiment in which both surface energy fluxes are turned off (NoF). Significantly, they show a similar reduction in polar-low intensity with only $1 \mathrm{hPa}$ differences up to about 0000 UTC on 20 December, with the NoF experiment showing the largest reduction in intensity thereafter (Figure 9(a)). The results of the above experiments indicate that moisture supply from the sea, available for condensational heating through moist convection, is not an important energy source in the mature stage of this polar low.

After the mature environmental conditions have been set up, the direct role of surface energy fluxes on the mature polar-low intensity is more clearly revealed by the delayed (D) experiments. Similar to the NoF, the NoF-D experiment suggests that the surface energy fluxes play a dominant role for the mature polar-low intensity since the polar low gradually weakens from 1 to $10 \mathrm{hPa}$ during the first 12 hours compared to the CTL (Figure 9). During the same period the absence of only sensible heat fluxes (NoSHF-D) shows a more moderate reduction in polar-low intensity (from 1 to $4 \mathrm{hPa}$ ) compared to the CTL (Figure 9). The absence of latent heat fluxes (NoLHF-D), on the other hand, shows only 1-2 hPa weaker polar low throughout relative to the CTL (not shown). Thus, after the mature environment conditions have been set up, sensible heat fluxes seem to be essential for the polar low itself while latent heat fluxes seem to play a minor role. The question remains: do the sensible heat fluxes affect the polar-low vortex directly or indirectly through modification of the polar-low environment? During the first three hours of integration (from 1200 UTC to 1500 UTC on 19 December) the absence of surface sensible heat fluxes (NoSHF-D) had little impact on the thermal structure of the polar-low environment (not shown). However, during this 3-hour period, the polar-low intensity weakened by $2 \mathrm{hPa}$ compared to the CTL (Figure 9), which suggests that sensible heat fluxes contribute directly to the polar-low intensity. The reduction in intensity thereafter could also be caused by the deformation of the polar-low environment (not shown), in agreement with Yanase et al. (2004).

Several authors (Harrold and Browning, 1969; Duncan, 1977; Bresch et al., 1997) have shown that baroclinic growth 


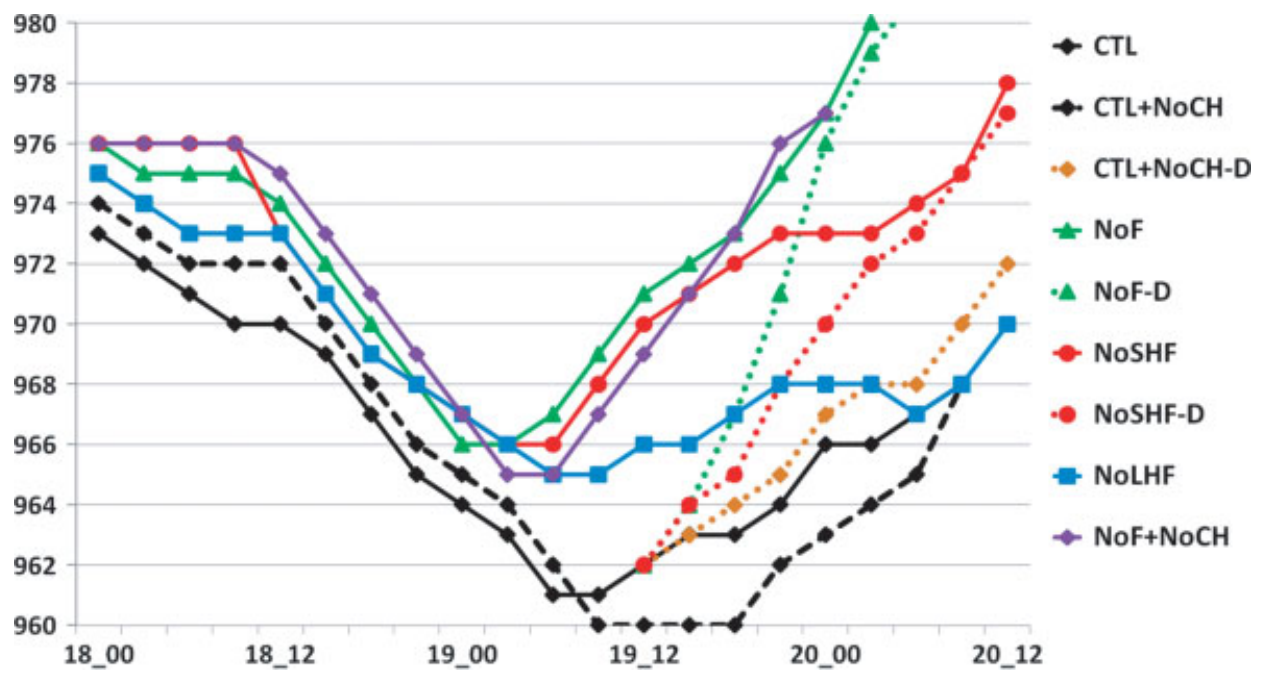

Figure 9. A 3-hour time evolution (date and hour) of minimum sea-level pressure (hPa) was utilized in the following experiments: CTL (black), $\mathrm{CTL}+\mathrm{NoCH}$ (dashed black), CTL+NoCH-D (dotted orange), NoF (green), NoF-D (dotted green), NoSHF (red), NoSHF-D (dotted red), NoLHF (blue) and NoF+NoCH (purple). The tracking starts at 0000 UTC 18 December 2002 and ends at 1200 UTC 20 December. The solid lines and the dashed line show experiments in which physical processes have been turned off throughout the simulation. The delayed (D) experiments are shown as dotted lines.

in polar-low developments is able to proceed only when the atmosphere possesses reduced stability at lower levels. According to Hoskins et al. (1985), the capability of a UPV anomaly to induce circulation at surface levels is dependent upon the static stability of the lower troposphere. This effect can be understood with the aid of the Rossby penetration depth $(H)$, which is related to the static stability of the troposphere through the relation $H \sim f L / N$, where $f$ is the Coriolis parameter, $N$ (the Brunt-Väisälä frequency) is a measurement of the static stability, and $L$ is the horizontal scale of the UPV anomaly (Rasmussen and Turner, 2003). Bresch et al. (1997) argued that the lower atmosphere became too stable (small $H$ ) for the upperlevel PV anomaly to initiate surface development when surface fluxes were turned off in their experiments. In their studies, the baroclinic zone was confined to lower atmospheric levels, which are affected by surface energy fluxes. However, the ECMWF analyses (Figure 3) and the CTL experiment (Figure 4) suggest that, in our case, deep baroclinicity is important for the development of the polar low and may explain why the polar-low intensity is not sensitive to surface flux modifications and condensational heating (NoF, NoF+NoCH, Figure 9(a)) until baroclinicity weakened after 0000 UTC on 19 December (Figure 5). A similar situation was reported in a polar low over the Pacific (Sardie and Warner, 1985), in that deep baroclinicity rather than surface fluxes was important for the development of the polar low.

A well-known hurricane theory applied to describe the role of surface energy fluxes for polar-low developments is the wind-induced surface heat exchange (WISHE) mechanism (Craig and Gray, 1996). The WISHE theory assumes a neutral atmosphere where moist convection mixes air through the troposphere, but does not cause any temperature perturbations at the vortex centre unless the PBL is anomalously heated as a result of surface fluxes of heat and moisture. The heated core of the vortex results in a stronger updraught and hence a stronger mass convergence at lower levels, causing a deepening of the vortex. The surface energy fluxes are wind speed dependent and, therefore, determined by the polar-low-scale flow, which results in a positive feedback mechanism between surface energy fluxes and surface wind speed (e.g. Craig and Gray, 1996). The reduced polar-low intensity (Figure 4 ), the reduction in surface energy fluxes (Figure 6) after the polar low has reached peak intensity, and the result of the sensitivity experiments (Figure 9), suggest a gradual transition from a polar low driven by dry baroclinic instability to one driven by sensible heat fluxes. As discussed in section 4, upper-level PV forcing may also be important for polar-low energetics at later stages of the polar low.

Interestingly, Figure 9 shows that condensational heating seems to have a slightly detrimental effect $(1-2 \mathrm{hPa})$ on polar-low intensity ( $\mathrm{NoF}+\mathrm{NoCH}$ versus $\mathrm{NoF}$, respectively) after the polar low has reached its peak intensity. The role of condensational heating is analysed in the subsection below.

\subsection{The role of condensational heating}

This subsection investigates the role of condensational heating in polar-low intensity using the CTL, CTL+NoCH and the CTL+NoCH-D experiments (Table 1).

Firstly, similar to the CTL experiment, all three simulations obtained (not shown) a deepening of the polar low (approximately $9 \mathrm{hPa}$ day $^{-1}$ ) up to about 0900 UTC on 19 December (Figure 9). Secondly, the polar-low intensity was relatively insensitive to the treatment of cloud microphysics and convection in the WRF model (Table 2).

During the polar-low deepening stage, the removal of condensational heating results in a $1-2 \mathrm{hPa}$ weaker polar low (CTL versus CTL+NoCH, Figure 9), which is in agreement with the discussion above, in that condensational heating seems to be irrelevant for the intensity of the polar low. In Figure 9, the most striking feature occurs after 1200 UTC on 19 December, during a period when baroclinicity all but vanishes (Figure 5), and the polar low is fuelled by sensible heat fluxes (Figure 9). In this period, condensational heating has a negative effect on polar-low intensity. By turning off condensational heating, a $1-4 \mathrm{hPa}$ deeper polar low is simulated (CTL+NoCH, Figure 9).

To our knowledge, this study is the first to report a negative effect of condensational heating on the deepening of a warm-core polar low. In the satellite images, deep, 
convective, spiral-like clouds ending at the eye wall are seen (Figure $1(\mathrm{c})$ and (e)). It would therefore have been reasonable to expect that condensational heating had a positive effect on polar-low intensity. Several previous casestudies of polar lows (e.g. Nordeng and Rasmussen, 1992; Mailhot et al., 1996; Bresch et al., 1997; Yanase et al., 2004) suggested that condensational heating is the main energy source of the polar lows. In a numerical polar-low study by Albright et al. (1995), the polar low was found to be driven by condensational heating even if sensible heat fluxes were 3-4 times larger than latent heat fluxes.

In order to address the direct role of condensational heating on the intensity of the mature polar low we need to analyse the delayed (D) experiments. In the delayed $\mathrm{CTL}+\mathrm{NOCH}-\mathrm{D}$ experiment, condensational heating turned out to be slightly positive, yielding a $1-2 \mathrm{hPa}$ deepening of the polar low compared to the CTL (Figure 9). However, after three hours of integration time, the CTL and the CTL+NoCH-D experiments show similar intensity (963 hPa, Figure 9). If condensational heating directly affected the polar-low vortex, a decrease in intensity would have been expected during this time period (e.g. Yanase et al., 2004). However, the relatively modest reduction $(1-2 \mathrm{hPa})$ in intensity seen thereafter suggests that condensational heating does not have any large direct or indirect effect on the mature polar-low energetics. This result appears to conflict with the more ordinary experiments in which condensational heating was turned off throughout the simulation (e.g. CTL+NoCH). The following subsection addresses this conflicting result.

\subsection{A comparison of the CTL, CTL $+\mathrm{NoCH}$ and NoSHF experiments}

The negative effects of condensational heating are studied from the PV perspective (e.g. see section 4.2) by comparing horizontal as well as vertical plots of PV for the CTL, $\mathrm{CTL}+\mathrm{NoCH}$ and NoSHF experiments. Moreover, the discussion in this subsection was found to fit all pairs of experiments with and without condensational heating (Table 2).

In Figure 10(a) and (c), PV at $500 \mathrm{hPa}$ and the height of the $500 \mathrm{hPa}$ surface are shown along with MSLP valid at 1200 UTC on 19 December for the CTL+NoCH and NoSHF experiments, respectively. The UPV anomaly is slightly more intense and smaller in the CTL+NoCH experiment (Figure 10(a)), but it is simulated at approximately the same location as in the NoSHF and CTL experiments $\left(73^{\circ} \mathrm{N}, 49^{\circ} \mathrm{E}\right.$, Figures 10(a) and (c) and 7(e)).

Figure 10(b) and (d) show the cross-sections of PV and the potential temperature for the CTL+NoCH and NoSHF experiments, respectively. Both experiments show features similar to the CTL experiment (Figure 7(f)), i.e. a UPV anomaly located between $70^{\circ} \mathrm{N}$ and $74^{\circ} \mathrm{N}$ reaching down to about $4 \mathrm{~km}$ height, a surface $\theta$ anomaly centred at the polarlow eye (red dot), constant potential temperature showing the well-mixed PBL, and a (1-5 PVU) LPV anomaly at the top of the PBL. As for the CTL experiment, the high PV air (1-5 PVU) stretching between the LPV and UPV anomalies (Figure 10(b) and (d)) is viewed as evidence of a phase lock between the anomalies (Montgomery and Farrell, 1992).

Downwind of the sea ice, strong convection triggered by the extreme sensible heat fluxes deepens the well-mixed PBL, resulting in a gradual destabilization and warming of the
PBL (Figures 7(f) and 10(b)). The absence of condensational heating in the $\mathrm{CTL}+\mathrm{NoCH}$ experiments means that there is no destruction of PV aloft causing the eastward-moving UPV anomaly (e.g. see Figure 7(c) and (e)) to be almost vertically aligned with the polar low in its mature stage (Figure 10(b)). As a result, the polar low in the $\mathrm{CTL}+\mathrm{NoCH}$ experiment is positioned farther south $\left(\sim 73^{\circ} \mathrm{N}\right)$ in a deeper and warmer PBL (Figure 10(b)) than seen in the CTL experiment $\left(\sim 74^{\circ} \mathrm{N}\right.$, Figure $\left.7(\mathrm{e})\right)$. As in the CTL experiment, the UPV anomaly moves eastward over Novaya Zemlya during the following 24 hours (not shown). The evidence of a phase lock between the polar low and the eastward-moving UPV anomaly in the CTL $+\mathrm{NoCH}$ experiment could explain the polar low's more southerly loop and landfall further north than seen in the CTL experiment (Figure 8). Notably, the smaller air-sea temperature differences in the CTL $+\mathrm{NoCH}$ experiment resulted in sensible heat fluxes that were about $10-15 \%$ lower than in the CTL experiment. Therefore, the negative effect of condensational heating is not caused by differences in sensible heat fluxes in the simulations.

Due to the weaker static stability in the $\mathrm{CTL}+\mathrm{NoCH}$ experiment, the atmospheric conditions are more favourable for interactions (large $H$ ) between the UPV anomaly and the polar low than in the CTL experiment (Figures 10(b) and 7(f), respectively). Along with the lack of PV destruction aloft, this may explain the slightly more intense UPV anomaly, which in turn results in stronger upper-level forcing and then a deepening of the polar low in the CTL+NoCH experiment (Figure 10(b) versus 7(f), respectively). Bresch et al. (1997) and Mailhot et al. (1996) showed that when surface energy fluxes in their experiments were turned off, the lower atmosphere became too stable (small $H$ ) for the UPV anomaly to induce polar-low development, which is not the case in our study (NoSHF, Figure 9). The evidence of a phase lock between the UPV anomaly and the polar low in the NoSHF experiment (Figure $10(\mathrm{~d})$ ), in spite of a statically stable atmosphere (small $H$ ), supports our hypothesis that the UPV anomaly also has a strong influence on surface development in later stages of the polar low.

As in the CTL experiment, in the NoSHF a phase lock between the UPV anomaly and the polar low (not shown) persisted until the polar low made landfall. However, an important difference between the CTL and the NoSHF is that in the NoSHF the UPV anomaly did not move over Novaya Zemlya until early 21 December, which is about $24 \mathrm{~h}$ later than in CTL (not shown). Thus, the polar low seems to make landfall at a time when the UPV anomaly moves over Novaya Zemlya in each experiment (e.g. CTL, CTL+NoCH, NoSHF and NoLHF). These observations suggest that the interaction between the UPV anomaly and the polar low is important in explaining the simulated polar-low track and life cycle. To what extent this can explain the differences between the life cycle in CTL and the observed one is difficult to answer.

The organization of convection could also explain the negative effect of condensational heating in the simulations. Nordeng and Rasmussen (1992) argued that the convection must be organized in such a way that air masses warmed and moistened by surface energy fluxes must ascend in the central structure of the polar low and less at its sides in order to have mass convergence and deepening of the cyclone. As seen in the CTL experiment, the distribution of the vertical velocity suggests that convection takes place throughout the 

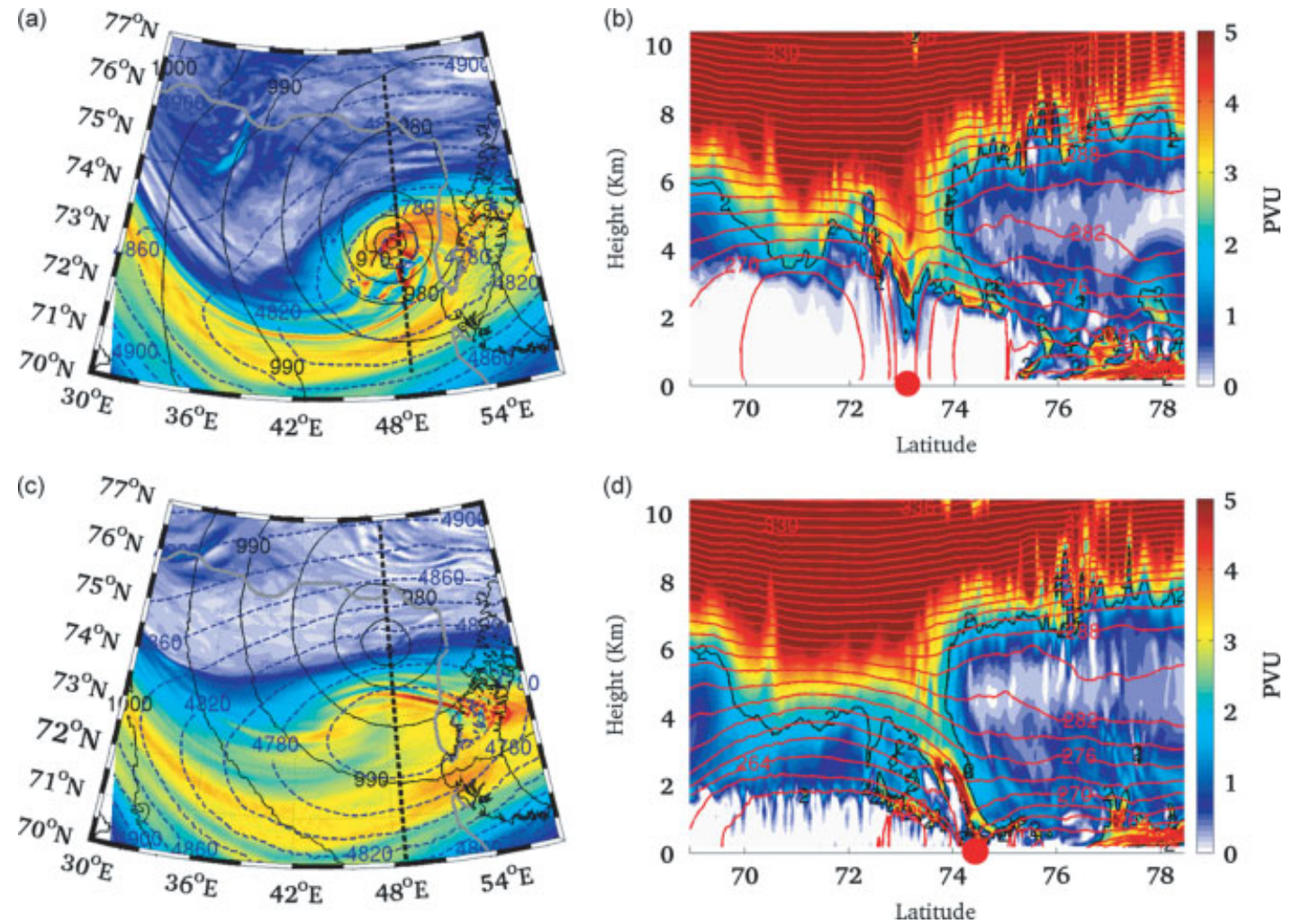

Figure 10. Left column: Potential vorticity (colour shading) and geopotential height (blue contours, $40 \mathrm{~m}$ interval) at $500 \mathrm{hPa}$ surface at $1200 \mathrm{UTC}$ 19 December 2002 from the (a) CTL $+\mathrm{NoCH}$ and (c) NoSHF experiments. The black solid lines shows sea-level pressure (5 hPa contours). The black dotted line shows the position of cross-section to the right. The sea ice edge is shown with a grey curve. Right column: Cross-section of PV and potential temperature at 1200 UTC 19 December from the (b) CTL+NoCH and (d) NoSHF experiments. 1 PVU unit is equivalent to SI units $1 \times 10^{-6} \mathrm{~m}^{2} \mathrm{~s}^{-1} \mathrm{~K} \mathrm{~kg}^{-1}$. The red dot marks the position of the polar low.
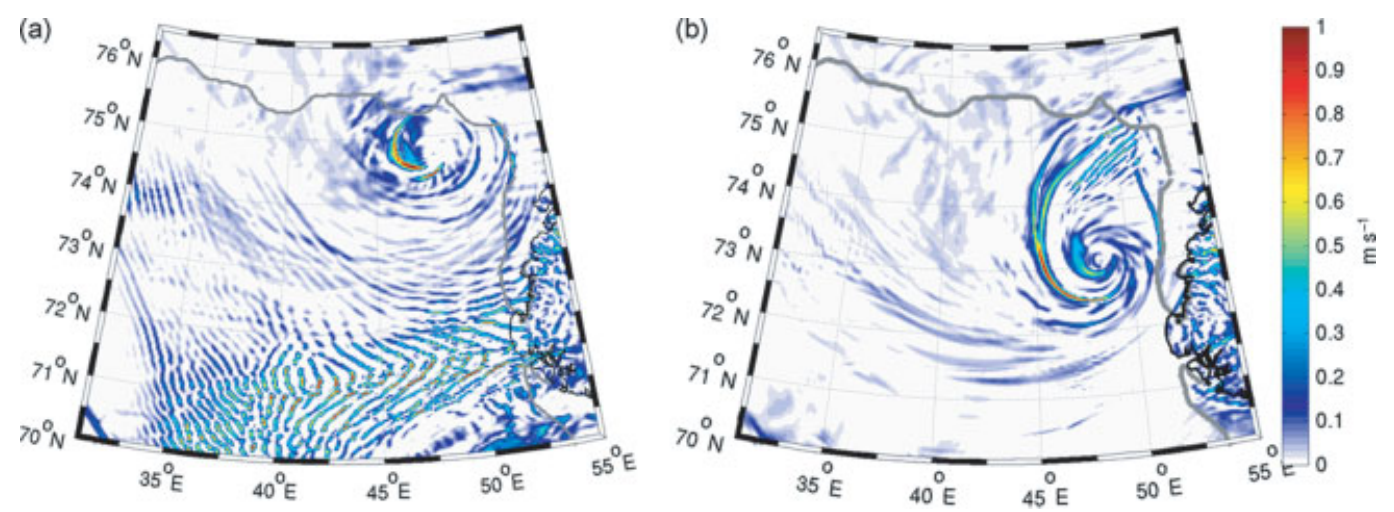

Figure 11. Vertical wind speed $\left(\mathrm{m} \mathrm{s}^{-1}\right.$, colour shading) at $850 \mathrm{hPa}$ surface form the (a) CTL and the (b) CTL+NoCH experiment valid at $1200 \mathrm{UTC}$ 19 December 2002. The sea ice edge is shown with a thick grey curve.

domain (Figure 11(a)), which is consistent with the cloud features seen in satellite images (Figure 2). However, in the $\mathrm{CTL}+\mathrm{NoCH}$ experiment the simulated convection is taking place at the central structure of the warm-core polar low $(\mathrm{CTL}+\mathrm{NoCH}$, Figure 11(b)), which is optimal for mass convergence and thus a deepening of the polar low. This result is consistent with van Delden (1989), who argued that the deepening of a cyclone is suppressed if the diabatic heating (e.g. moist convection) is located dynamically too far away from the cyclone centre as in the CTL experiment.

\section{Summary and concluding remarks}

An unusually deep (961 hPa) hurricane-like polar low that evolved over the Barents Sea during 18-21 December 2002 was numerically studied using the WRF model with a $3 \mathrm{~km}$ horizontal mesh. Satellite images reveal that the polar low developed close to the sea ice edge in the aftermath of an eastward-moving synoptic-scale low west of Novaya Zemlya on 18 December 2002. Similar to tropical hurricanes, spiral cloud bands surrounding a cloud-free eye were seen in the satellite images. The low dissipated as it made landfall at Novaya Zemlya $\left(75^{\circ} \mathrm{N}, 60^{\circ} \mathrm{E}\right)$ during the morning of 21 December.

The full-physics experiment (CTL) produced an intense cyclone $(961 \mathrm{hPa})$ that had characteristics similar to the observed polar low, but made landfall about 24 hours too early, according to the satellite images. Horizontal as well as vertical plots of $\mathrm{PV}$ indicate that the simulated polar low was 
a result of interaction between an eastward-moving upperlevel PV anomaly and deep baroclinicity (e.g. Montgomery and Farrell, 1992; Grønås and Kvamstø, 1995). Similar interactions were suggested in previous studies of similar events (Businger and Baik, 1991; Nordeng and Rasmussen, 1992). The simulated eye-like structure with a clear, calm, warm core with highest surface wind speed $\left(<25 \mathrm{~m} \mathrm{~s}^{-1}\right)$ in the eye wall is consistent with simulations of previous casestudies of similar events (Businger and Baik, 1991; Nordeng and Rasmussen, 1992). Similar to satellite observations, the model successfully simulated cloud streets. The polar low's close proximity to the sea ice and high surface wind speed $\left(25 \mathrm{~m} \mathrm{~s}^{-1}\right)$ triggered strong cold advection, resulting in extreme surface fluxes at the eye wall in its deepening stage. Maximum sensible and latent heat fluxes were about $1200 \mathrm{~W} \mathrm{~m}^{-2}$ and $400 \mathrm{~W} \mathrm{~m}^{-2}$, respectively. As the polar low weakened while it moved southward into a warmer PBL, maximum sensible and latent heat fluxes decreased to about $600 \mathrm{~W} \mathrm{~m}^{-2}$ and $300 \mathrm{~W} \mathrm{~m}^{-2}$, respectively.

Several high-resolution ( $3 \mathrm{~km}$ mesh) sensitivity experiments were conducted with the state-of-the-art WRF model to elucidate the underlying physics of the polar low. Two types of sensitivity experiments were designed. First, an ordinary type of sensitivity experiment was carried out, in which physical processes such as condensational heating and sensible and/or latent heat fluxes were turned off throughout the whole integration time. A second group of experiments was designed in which the physical properties were turned off after the polar low had reached its peak intensity. In these latter experiments, it was simpler to analyse whether a physical process affected the mature vortex itself or indirectly through modification of the polar-low environment.

Based on the analysis of the sensitivity experiments, we arrived at the following conclusions:

- The deepening of the polar low was a result of baroclinic energy conversion and upper-level PV forcing.

The complex interaction between surface energy fluxes, condensational heating, upper-level PV forcing and baroclinic dynamics makes it difficult to separate their role in the deepening stage of the simulated polar low. Still, the polar low developed in a deep baroclinic zone bounding relatively warm sub-polar and Arctic air masses, which most likely explains why the simulated polar-low intensity was not sensitive to surface energy fluxes and condensational heating modifications until the baroclinicity weakened.

- After the deepening stage, sensible heat fluxes and upper-level PV forcing fuelled the polar low, with a minor role for latent heat fluxes.

We suggest that the WISHE mechanism, as presented for polar lows by Craig and Gray (1996), is a likely forcing mechanism that gradually becomes more important after the polar-low deepening stage. However, in contrast to most previous case-studies of polar lows and tropical hurricanes, the polar-low energetics in this study were fuelled by sensible heat fluxes, with latent heat fluxes playing a secondary role. Indications of a phase lock between the upper-level $\mathrm{PV}$ anomaly and the polar low regardless of static stability at lower levels suggests strong upper-level PV forcing throughout the life cycle of the polar low.

- Condensational heating plays a minor role during the polar-low development.
The delayed (D) experiments showed that condensational heating had a slightly positive effect on the polar-low intensity after its deepening stage. This result appears to conflict with the experiments in which condensational heating was turned off throughout the whole integration time in that condensational heating then had a negative effect on the polar-low intensity after its deepening stage. Two factors may explain these unusual results: (1) when the condensational heating was turned off throughout the whole integration time, the cross-sections of PV and potential temperature suggest that the simulated polar low acquired a more conducive atmosphere for stronger upper-level PV forcing; (2) in the experiments without latent heat release, the simulated convection was organized at the central structure of the polar low, which is optimal for mass convergence and thus deepening of the cyclone.

Polar lows have previously been classified by their appearance in satellite images, their origin, and their forcing mechanisms. However, hurricane-like polar lows are not included in today's classification scheme (e.g. Wilhelmsen, 1985; Bracegirdle and Gray, 2008). Bracegirdle and Gray (2008) recommended that hurricane-like polar lows should form a separate class in a new classification scheme. As this study indicates, they may have characteristics that are unusual compared with other polar-low cases. In order to generalize our findings, more case-studies need to be carried out. For future work, we especially urge other authors to carry out the two types of sensitivity experiments presented in Yanase et al. (2004) concerning condensational heating as well as surface energy fluxes, in addition to switching off each type of surface flux ( $\mathrm{SH}$ and $\mathrm{LH}$ ) separately, in order to clarify their roles in polar-low developments. As shown in the present study, the use of the new type of sensitivity experiments may lead to improved insight in the underlying physics of polar lows.

\section{Acknowledgements}

This study has received support from the Norwegian Research Council through the project 'THORPEX-IPY: Improved forecasting of adverse weather in the Arctic - present and future' (grant no. 175992). The authors are grateful to WRF-help and Greg Thompson at NCAR for support on configurations of sensitivity experiments and the set-up of the WRF model. In particular, the authors wish to thank Gunnar Wollan and Simen Gaure for support on implementation of WRF at the University of Oslo. The first author wishes particularly to thank Bjørn Egil Nygård and Øyvind Hodnebrog for support with Matlab and WRF, and special thanks go to Gunnar Noer at the Norwegian Meteorological Institute for valuable discussion. To all my colleagues at MetOs, thanks for your motivating support and discussions.

\section{References}

Albright MD, Reed RJ, Ovens DW. 1995. Origin and structure of a numerically simulated polar low over Hudson Bay. Tellus 47: 834-848. Bracegirdle TJ, Gray SL. 2008. An objective climatology of the dynamical forcing of polar lows in the Nordic seas. Int. J. Climatol. 28: 1903-1919. Bracegirdle TJ, Gray SL. 2009. The dynamics of a polar low assessed using potential vorticity inversion. Q. J. R. Meteorol. Soc. 135: 880-893. 
Bresch JF, Reed RJ, Albright MD. 1997. A polar-low development over the Bering Sea: Analysis, numerical simulation, and sensitivity experiments. Mon. Weather Rev. 125: 3109-3130.

Businger S, Baik J-J. 1991. An Arctic hurricane over the Bering Sea. Mon. Weather Rev. 119: 2293-2322.

Businger S, Reed RJ. 1988. Cyclogenesis in cold air masses. Weather and Forecasting 4: 133-156.

Chen F, Dudhia J. 2001. Coupling an advanced land surface-hydrology model with the Penn State-NCAR MM5 modeling system. Part I: Model implementation and sensitivity. Mon. Weather Rev. 129: $569-585$.

Claud C, Heinemann G, Raustein E, Mcmurdie L. 2004. Polar low le Cygne: Satellite observations and numerical simulations. Q. J. R. Meteorol. Soc. 130: 1075-1102.

Craig GC, Gray SL. 1996. CISK or WISHE as the mechanism for tropical cyclone intensification. J. Atmos. Sci. 53: 3528-3540.

Dudhia J. 1989. Numerical study of convection observed during the Winter Monsoon Experiment using a mesoscale two-dimensional model. J. Atmos. Sci. 46: 3077-3107.

Duncan CN. 1977. A numerical investigation of polar lows. Q. J. R. Meteorol. Soc. 103: 255-267.

Emanuel KA, Rotunno R. 1989. Polar lows as Arctic hurricanes. Tellus 41A: $1-17$.

Føre I, Kristjánsson JE, Saetra Ø, Brevik O, Røsting B, Shapiro M. 2011. The full life cycle of a polar low over the Norwegian Sea observed by three research aircraft flights. Q. J. R. Meteorol. Soc. 137: 1659-1673.

Grønås S, Kvamstø NG. 1995. Numerical simulations of the synoptic conditions and development of Arctic outbreak polar lows. Tellus 47A: 797-814.

Grønås S, Skeie P. 1999. A case study of strong winds at an Arctic front. Tellus 51A: 865-879.

Harrold TW, Browning KA. 1969. The polar low as a baroclinic disturbance. Q. J. R. Meteorol. Soc. 95: 710-723.

Hoskins BJ, McIntyre ME, Robertson AE. 1985. On the use and significance of isentropic potential vorticity maps. Q. J. R. Meteorol. Soc. 111: 877-946.

Hong S-Y, Lim J-OJ. 2006. The WRF single-moment 6-class microphysics scheme (WSM6). J. Korean Meteorol. Soc. 42: 129-151.

Hong S-Y, Noh Y, Dudhia J. 2006. A new vertical diffusion package with an explicit treatment of entrainment processes. Mon. Weather Rev. 134: $2318-2341$.

Janjić ZI. 1994. The step-mountain eta coordinate model: Further developments of the convection, viscous sublayer, and turbulence closure schemes. Mon. Weather Rev. 122: 927-945.

Janjić ZI. 1996. 'The surface layer in the NCEP Eta Model.' In Eleventh Conference on Numerical weather prediction, Norfolk, Virginia, 19-23 August 1996. American Meteorological Society: Boston.

Kolstad EW. 2006. A new climatology of favourable conditions for reverse-shear polar lows. Tellus 58A: 344-354.

Kolstad EW, Bracegirdle TJ. 2008. Marine cold-air outbreaks in the future: An assessment of IPCC AR4 model results for the Northern Hemisphere. Clim. Dyn. 30: 871-885.

Liu AQ, Moore GWK, Tsuboki K, Renfrew IA. 2006. The effect of the sea-ice zone on the development of boundary-layer roll clouds during cold air outbreaks. Boundary-Layer Meteorol. 118: 557-581.

McInnes H, Kristiansen J, Kristjánsson JE, Schyberg H. 2011. The role of horizontal resolution for polar low simulations. Q. J. R. Meteorol. Soc. 137: 1674-1687.

Mailhot J, Hanley D, Bilodeau B, Hertzman O. 1996. A numerical case study of a polar low in the Labrador Sea. Tellus 48A: 383-402.
Martin R, Moore GWK. 2006. Transition of a synoptic system to a polar low via interaction with the orography of Greenland. Tellus 58A: 236-253.

Mlawer EJ, Taubman SJ, Brown PD, Iacono MJ, Clough SA. 1997. Radiative transfer for inhomogeneous atmospheres: RRTM, a validated correlated-k model for the longwave. J. Geophys. Res. 102: $16663-16682$.

Montgomery MT, Farrell BF. 1992. Polar low dynamics. J. Atmos. Sci. 49: $2484-2505$.

Nordeng TE, Rasmussen EA. 1992. A most beautiful polar low: A case study of a polar low development in the Bear Island region. Tellus 44A: 81-99.

Plant RS, Craig GC, Gray SL. 2003. On a threefold classification of extratropical cyclogenesis. Q. J. R. Meteorol. Soc. 129: 2989-3012.

Rasmussen E. 1979. The polar low as an extratropical CISK disturbance. Q. J. R. Meteorol. Soc. 105: 531-549.

Rasmussen EA, Turner J. 2003. Polar Lows. Cambridge University Press.

Renfrew IA, Moore GWK, Guest PS, Bumke K. 2002. A comparison of surface layer and surface turbulent flux observations over the Labrador Sea with ECMWF analyses and NCEP reanalyses. J. Phys. Oceanogr. 32: $383-400$

Renfrew IA, Petersen GN, Sproson DAJ, Moore GWK, Adiwidjaja H, Zhang S, North R. 2009. A comparison of aircraft-based surfacelayer observations over Denmark Strait and the Irminger Sea with meteorological analyses and QuikSCAT winds. Q. J. R. Meteorol. Soc. 135: 2046-2066.

Sardie JM, Warner TT. 1985. A numerical study of the development mechanisms of polar lows. Tellus 37A: 460-477.

Shapiro MA, Fedor LS, Hampel T. 1987. Research aircraft measurements of a polar low over the Norwegian Sea. Tellus 39A: 272-306.

Skamarock WC, Klemp JB, Dudhia J, Gill DO, Barker DM, Wang W, Powers JG. 2007. 'A description of the Advanced research WRF version 2.' NCAR Technical Note TN 468+STR, National Center for Atmospheric Research, Boulder, Colorado, USA.

Thompson G, Rasmussen RM, Manning K. 2004. Explicit forecasts of winter precipitation using an improved bulk microphysics scheme. Part I: Description and sensitivity analysis. Mon. Weather Rev. 132: 519-542.

Thompson G, Field PR, Hall WD, Rasmussen RM. 2006. 'A new bulk microphysical parameterization for WRF (\& MM5).’ Pp 1-11 in Session05 of Proceedings of the 7th Weather Research and Forecasting model Workshop, NCAR Mesoscale and Microscale Meteorology Division, Boulder, Colorado, USA. http://www.mmm. ucar.edu/wrf/users/workshops/

Trenberth KE, Fasullo J. 2008. Energy budgets of Atlantic hurricanes and changes from 1970. Geochem. Geophy. Geosy. 9: Q09V08, DOI: 10.1029/2007GC001847.

van Delden A. 1989. On the deepening and filling of balanced cyclones by diabatic heating. Meteorol. Atmos. Phys. 41: 127-145.

Wilhelmsen K. 1985. Climatological study of gale-producing polar lows near Norway. Tellus 37A: 451-459.

Wu LT, Petty GW. 2010. Intercomparison of bulk microphysics schemes in model simulations of polar lows. Mon. Weather Rev. 138: 2211-2228.

Wu LT, Martin JE, Petty GW. 2011. Piecewise potential vorticity diagnosis of the development of a polar low over the Sea of Japan. Tellus 63A: 198-211.

Yanase Y, Fu G, Niino H, Kato T. 2004. A polar low over the Japan Sea on 21 January 1997. Part II: A numerical study. Mon. Weather Rev. 132: $1552-1574$. 